\title{
Fishing Boat Design Based Local Wisdom in Southeast Sulawesi Fishermen
}

\author{
Agus Wahyu Santoso ${ }^{1}$, Yopi Novita ${ }^{2}$, Budhi H. Iskandar ${ }^{2}$, Mulyono S. Baskoro \\ ${ }^{1}$ Ministry of Maritime Affairs and Fisheries of the Republic of Indonesia, Jakarta, Indonesia \\ ${ }^{2}$ Department of Fisheries Resource Utilization, Bogor Agricultural Institute, Bogor, Indonesia
}

\section{Email address:}

agusws@yahoo.com (A.W. Santoso)

\section{To cite this article:}

Agus Wahyu Santoso, Yopi Novita, Budhi H. Iskandar, Mulyono S. Baskoro. Fishing Boat Design Based Local Wisdom in Southeast Sulawesi Fishermen. American Journal of Software Engineering and Applications. Vol. 9, No. 1, 2020, pp. 1-18. doi: 10.11648/j.ajsea.20200901.11

Received: August 7, 2019; Accepted: September 5, 2019; Published: May 18, 2020

\begin{abstract}
Kendari is one of the cities in Southeast Sulawesi that has a potential for abundance of fish resources. That's why there are so many fisheries ships that will be allocated to the area. But the large number of refusal of the aid vessel needs to be carried out studies related to the design of aid ships that are in accordance with local wisdom so that the intended aid vessels can be accepted by fishermen. The objectives of this study are (1) To describe the existing conditions of the light fishing vessel fleet in Southeast Sulawesi (2) Estimate the level of stability of light fishing vessels in Southeast Sulawesi. The data was collected using a survey method by collecting observational and measurement data on the fishing vessel, the shape and main dimensions of the ship. The data processing used is numerical equations, then the data analysis was done using a numerical and descriptive comparison method. Maxsurf licensed software was used in this method. The feasibility of a ship's sea is reviewed by looking at its stability capability, motion resistance and rolling period. In the ship design group in Southeast Sulawesi, namely handline ships with light fishing, there are 3 parts, namely vessels with large, medium and small groups. Of the three groups, all bow-shaped high designs are raked bow landai which indicates that the shape of the ship there is uniform in terms of the height of the ship's bow. The design also has a different longitudinal cross section, namely double pointed for groups of vessels with small and transom for large and medium size. Based on the simulation results, the ship with a medium has the best stability value between the two types of large and small groups. Based on the ability of motion detainees, ships with a medium group size have the greatest value of resistance because for boats with handline fishing equipment do not require speed because of the type of passive fishing gear. Based on the rolling period value of ships with medium, large and small group having values according to requirements according to FAO, 1996, namely TR=4.5-7.0 seconds. The longitudinal strength in superior fishing boat design research can be convincing to recipient fishermen that fiberglass material already in accordance with the rules. The results of the study show that the Hand Line 5 GT ships were chosen by fishermen to be selected as aid vessels.
\end{abstract}

Keywords: Fishing Vessel Design, Local Wisdom Southeast Sulawesi

\section{Introduction}

The government, in this case the Ministry of Maritime Affairs and Fisheries is promoting the fishing boat procurement program for fishermen. One of the goals is to prosper fishermen with the assistance program referred to, especially with foreign fishing vessels not permitted to operate in the territorial waters of the Republic of Indonesia. The problem that arises from this program is the existence of several cases of refusal of fishermen to aid vessels. The impact of such refusal will result in the aid ship being abandoned and will have an impact on the State's losses. One factor of fishermen rejection is the design of fishing boats that are not in accordance with the wisdom of local fishermen. This condition is supported by several studies conducted by [1] shows that there are doubts of fishermen on aid vessels that lie in the operational capability of aid fishing vessels to the maximum extent that they operate on ZEEI Indonesia. Procurement of the ship is reaping various problems such as wrong designation, inadequate vessel specifications and difficulty operating.

One area that receives quite a lot of aid ships is $37 \%$ of the 
total number of aid ships and the high effort to reject the aid ships is Southeast Sulawesi. This is because the design of fishing vessels in Indonesia is very diverse. The study conducted by [2] show that there is diversity in the forms of fishing vessel kasko. Where the diversity is not caused by differences in operating methods, but due to the customs of the ship craftsmen in the area. Another study is [3] which shows that there is diversity in the shape of the bow of fishing vessels, and that diversity is not caused by differences in the characteristics of the waters in which the ship is operated. But more to the custom of local ship craftsmen in making the shape of the bow of the ship. Actually in theory [4], the factors that must be considered in the formulation of the design of a fishing vessel, especially those related to the shape of the ship are the water characteristics and the fishing methods to be operated.

This study was conducted with the aim of obtaining the design of light fishing vessels in accordance with the local wisdom of fishermen in Southeast Sulawesi, especially fishermen in Kendari. Good fishing vessel design, not only seaworthy, operation-worthy and seaworthy, but also acceptable to fishermen who will use it. The receipt of the aid ship by fishermen can eliminate state losses and the waste of state funds that have been spent. In addition, the existence of suitable vessels is expected to increase the effectiveness and efficiency in fishing operations conducted by fishermen. With this study, it is hoped that the fishing boat assistance program can truly achieve the expected goals so that in the future the ship giving program will be better in its implementation and continue to prosper for the welfare of small fishermen in the territory of Indonesia.

\section{Method}

The study was conducted at the Kendari Ocean Fishery Port and the Kendari Fish Landing Port in Southeast Sulawesi. Ministry of Maritime Affairs and Fisheries (KKP) and the Kendari and surrounding areas. Observations and data collection in the field were conducted in July 2017 November 2018. Data was collected in several stages until complete data was obtained. Research locations are presented in Figure 1.

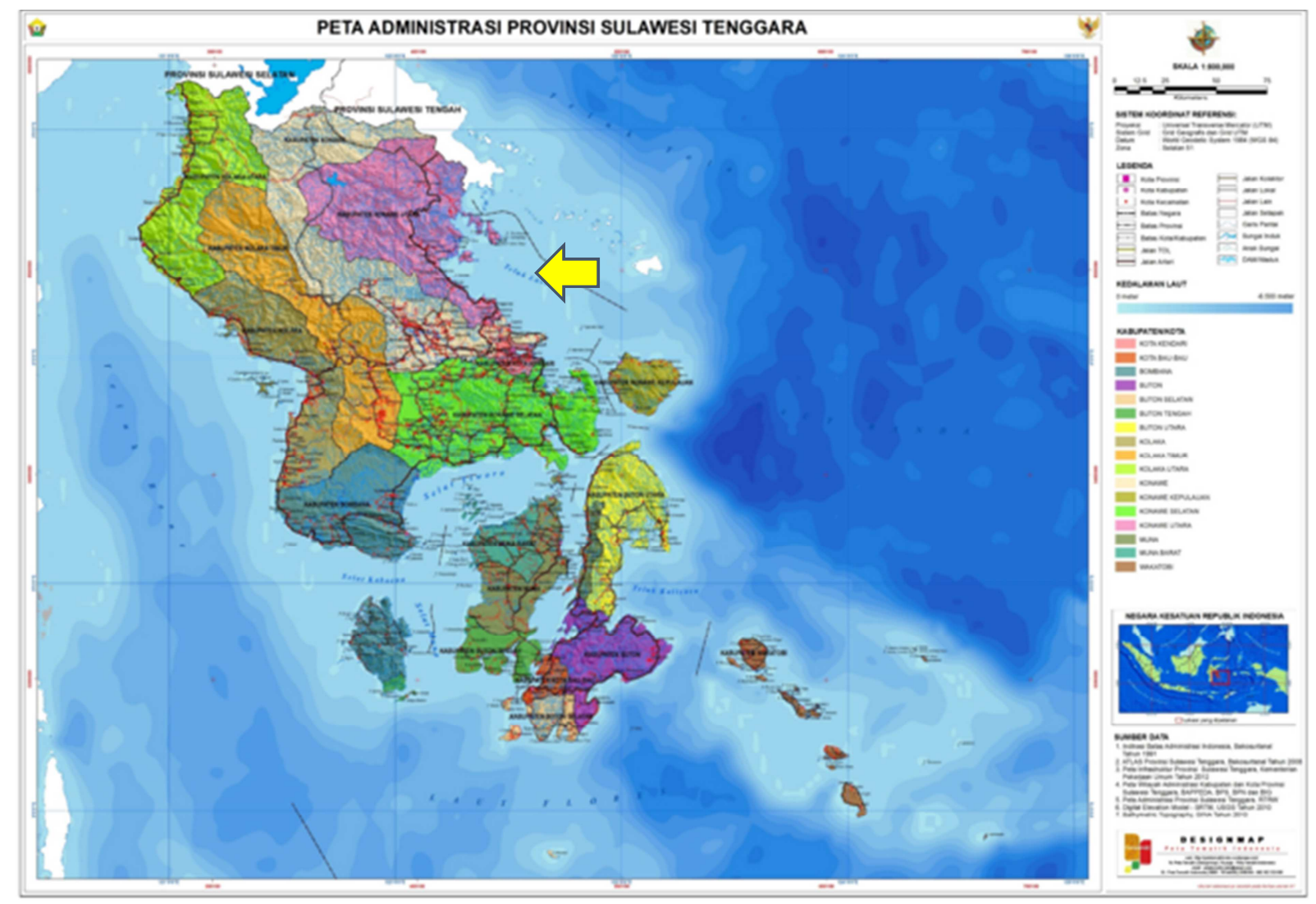

Figure 1. Map of research location.

\subsection{Purpose}

The purpose of this research is:

1. Describe the condition of the existing fleet of light fishing vessels in Southeast Sulawesi;

2. Estimating the level of stability, rolling motion and resistance of light fishing vessels in Southeast Sulawesi;

\subsection{Types and Data Collection}

The data used in this study consisted of primary data, namely sampling of fishing vessels at the survey location such as the main size of the ship, the tilt of the bow, and the shape of the ship's shafts and secondary data such as distribution data and the number of fishing vessels in 
Southeast Sulawesi Province in the form of data reports capture fisheries statistics of Southeast Sulawesi Province. Referring to the results of the field, there were 32 units of fishing vessels operating using a handline fishing gear. Furthermore, vessel dimension data is processed to obtain the ratio of the main dimensions consisting of $\mathrm{L} / \mathrm{B}, \mathrm{L} / \mathrm{D}$ and $\mathrm{B} / \mathrm{D}$. Then do the following steps:

1. Created Classification where (Lmax-Lmin: 3), obtained the number of ships:

a. Classification 1 or ships of large size category, number 10 ships then take $10 \%$ then there is 1 ship then made lines plan.

b. Classification 2 or ships of medium size category, number 11 ships then take $10 \%$ then there is 1.1 rounded to 1 ship then made lines plan.

c. Classification 3 or ships of small size, number 11 ships then take $10 \%$ then there is 1.1 rounded to 1 ship then made lines plan.

2. Observe the similarities between lines plans in each class and see the similarities between lines plans in different classes.

3. The design of the ship design will be grouped by:
a. Ship Stability.
b. Rolling motion.
c. Ship Resistance.

4. Results of Grouping: Of the three lines plan models above after being analyzed for the shape of the ship kasko below the water line have a similar shape. The only difference is the shape of the building above both the position of the ship building for the rudder of the ship and the shape of the hatch in the deck.

5. Similarities in the design of fishing vessels in Kendari waters after observing in this study are as follows:

a. Almost all ships with decks are machined, and only a third of the boats without decks have engines, generally external engines that are separate from the hull. And most of the boats are traditionally made boats that are operated with sails and oars.

b. Ships with fiberglass made of fiberglass have begun to be widely used by fishermen, although there are still many fishermen still using boats with wooden shafts.

c. The fishing gear used still uses a lot of nets, both purse seine and gill nett. However, with the introduction of ships using lights or light fishing, the fishing gear used by fishermen have started using fishing rods, both handline and longline fishing lines.

\subsection{Data Proczessing}

Data processing in this study is carried out in stages in accordance with the objectives of the study so that the stages of data processing will be described in stages in accordance with the objectives to be obtained.

Existing Condition of Ship Shape in Kendari Area

\subsubsection{Main Dimensions}

Information on the main dimensions of ships in the
Kendari area such as length, width and height of the ship will be processed in tabular form. According to [5] the main dimensions of a ship can show the performance of stability, speed, elongation strength, movement and resistance of the ship. In addition, the magnitude of the comparison of the main dimensions can also affect the construction of a ship [6]. The performance is obtained by comparing the data in the main dimesni using the following mathematical equations:

a) Rasio dimention $\mathrm{L} / \mathrm{B}$

$$
\frac{L}{B}=\frac{\text { Length }}{\text { Breadth }}
$$

b) Rasio dimention $\mathrm{L} / \mathrm{D}$

$$
\frac{L}{D}=\frac{\text { Length }}{\text { Depth }}
$$

c) Rasio dimention $\mathrm{B} / \mathrm{D}$

$$
\frac{B}{D}=\frac{\text { Breadth }}{\text { Depth }}
$$

\subsubsection{Stern Bow}

Ship stern bow height measurements are measured by calculating the distance between the highest height to the lowest part of the ship or what is usually called the keel. In addition, measurement of the ship's tilt is measured by calculating the distance from the upright plane of the bow to the tilt of the ship's bow. The results of the observation and measurement of the bow height are then processed in the form of tables and figures. Sketch of the measurement of the height of the bow is displayed as shown 2 .

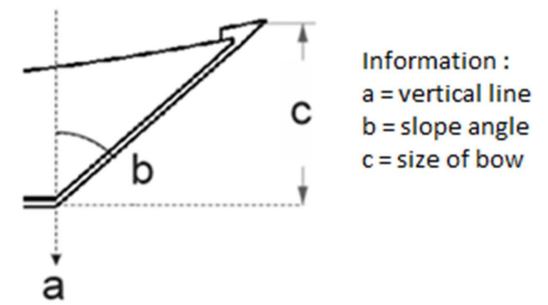

(Source: Bangun et al. 2017)

Figure 2. The shape of the hull shape of the boat.

\subsubsection{Shape Body and Building on Board}

The condition of ships in the Kendari region apart from the main dimensions and height, the shape of the hull needs to be identified to see the diversity created. The shape of the hull to be identified is a longitudinal and transverse shape According to [7] the shape of the ship's head can determine the loading capacity, stability, movement and resistance of the ship The value of ship resistance is one of the important factors to consider in designing the shape of the ship's board because it can affect the power and speed of the ship The length of the hull can be identified by looking at the shape of the waterplan area In addition, the shape of the hull is transversely identified by looking at the shape of the ship's midship observations of the shape of the hull will then be processed into image form in addition, the shape of the ship's building will also be identified to show differences in the 
area ship building forms will be presented in the form of images.

\subsection{Technical Study of Ship Handlines in the Kendari Area}

\subsubsection{Linesplan Dan General Arrangement}

Ships representing each group are presented with lines plan images to see the differences.[8] explains that the lines plan is a picture that shows the print outline plan of a ship that has an appropriate scale and consists of a plan (half breadth plan), body plan, profile (profile plan) ines plan images are obtained by processing data such as the dimensions of the main dimensions and curvature of the hull into the shape of the image he lines plan drawing is then used for the basis of making general arrangements.

General arrangement is a picture showing a view of the arrangement and position of all equipment, cargo and goods on the deck of the ship including fishing gear, fishing aids, superstructure, masts and others from several points of view [4] aking a general arrangement is done by processing the data position of the position of the cargo load on the ship he vessels used are vessels that are representative of each group of ships.

\subsubsection{Hydrostatic Parameters}

Hydrostatic parameters are values that describe the performance of a ship statically in water [9] ydrostatic arameter values obtained using the naval architecture equation are presented in tabular form he formula for the naval architecture equation is shown as follows [10]:

a) Waterplane area (Aw), with formula Simpson I

$$
\mathrm{Aw}=\mathrm{h} / 3\left(\mathrm{Y}_{0}+4 \mathrm{Y}_{1}+2 \mathrm{Y}_{2}+\ldots .+4 \mathrm{Y}_{\mathrm{n}}+\mathrm{Y}_{\mathrm{n}+1}\right)
$$

b) Volume displacement $(\nabla)$, with formula Simpson I

$$
\nabla=h / 3\left(\mathrm{~A}_{0}+4 \mathrm{~A}_{1}+2 \mathrm{~A}_{2}+\ldots .+4 \mathrm{~A}_{\mathrm{n}}+\mathrm{A}_{\mathrm{n}+1}\right)
$$

c) Ton displacement ( $\mathbf{\Delta})$

$$
\mathbf{\Delta}=\nabla x \rho
$$

d) Ton Per Centimeter (TPC), with formula

$$
\mathrm{TPC}=(\mathrm{Aw} / 100) \times 1,025
$$

e) Coefficient of Block $(\mathrm{Cb})$

$$
\mathrm{Cb}=\nabla /(\mathrm{L} \times \mathrm{B} \times \mathrm{d})
$$

f) Coefficient of Midship $\left(\mathrm{C}_{\otimes}\right)$

$$
\mathrm{C}_{\otimes}=\mathrm{A}_{\otimes} /(\mathrm{B} \times \mathrm{d})
$$

g) Coefficient of Prismatic (Cp)

$$
\mathrm{Cp}=\nabla /\left(\mathrm{A}_{\otimes} \mathrm{x} L\right)
$$

h) Coefficient of Vertical Prismatic (Cvp)

$$
\mathrm{Cvp}=\nabla /(\text { Aw } \mathrm{x} \mathrm{d})
$$

i) Coefficient of Waterplan $(\mathrm{Cw})$

$$
\mathrm{Cw}=\mathrm{Aw} /(\mathrm{L} \times \mathrm{B})
$$

j) The distance of the floating point (B) to the keel (K), with formula

$$
\mathrm{KB}=1 / 3[2,5 \mathrm{~d}-(\nabla / \mathrm{Aw})]
$$

k) Distance of floating point (B) to point of metacentre (M), with formula

$$
\mathrm{BM}=\mathrm{I} / \nabla
$$

1) Distance of metacentre point $(\mathrm{M})$ to relief $(\mathrm{K})$, with formula

$$
\mathrm{KM}=\mathrm{KB}+\mathrm{BM}
$$

m)Distance of longitudinal metacentre points $\left(\mathrm{BM}_{\mathrm{L}}\right)$ can be calculated with formula

$$
\mathrm{BM}_{\mathrm{L}}=\mathrm{I}_{\mathrm{L}}+\nabla
$$

n) The distance of the longitudinal metacentre point to the keel $\left(\mathrm{KM}_{\mathrm{L}}\right)$ can be calculated with formula

$$
\mathrm{KM}_{\mathrm{L}}=\mathrm{KB}+\mathrm{BM}_{\mathrm{L}}
$$

o) Distance weight point $(\mathrm{G})$ to relief $(\mathrm{K})$, with formula

$$
\mathrm{KG}=\mathrm{I} /
$$

p) Weighted point distance $(\mathrm{G})$ to relief $(\mathrm{K})$, with formula

$$
\mathrm{GM}=\mathrm{KM}-\mathrm{KG}
$$

With to:

$\mathrm{h}=$ The distance between the ordinate on the water line (WL) to-i

$\mathrm{Y}_{\mathrm{n}}=$ Width on the ordinate to- $\mathrm{n}(\mathrm{m})$

$\mathrm{A}=$ Broad on WL to-i $\left(\mathrm{m}^{2}\right)$

$\rho=$ Seawater density $\left(1,025 \mathrm{ton} / \mathrm{m}^{3}\right)$

$\mathrm{L}=$ Length of the ship (m)

$\mathrm{B}=$ Depth ship $(\mathrm{m})$

$\mathrm{d}=$ Draft $\operatorname{ship}(\mathrm{m})$

$\mathrm{A}_{\otimes}=$ Midship area $\left(\mathrm{m}^{2}\right)$

$\mathrm{I}=$ Moment innertia

\subsubsection{Stabilitas}

Vessel stability is the ability of a ship to return to its original position after experiencing pulling forces from outside or inside the ship which causes the ship to wobble [11] actors that can change the stability of a ship are the center of gravity and the center of bouyancy ccording to [12] the center of gravity is the resultant point of gravity for all parts of the ship, including all the contents inside, which press downwards urthermore, the floating point is the geometrical center of gravity of the ship that is immersed in water that presses upward and the metacenter point is the height of the inclination angle of the ship's keel and the center point of the line that works the buoyancy and gravity $f$ the gravitational point and the floating point are not vertically aligned, then the ship's moment will appear in the direction the moment moves [13]. 
The value of the returning / coupling arm (GZ) will then be the stability parameter of a ship which will be presented in the form of a curve he curve illustrates the relationship between the GZ value and the various angles of the ship's slope in a fixed ton displacement [14] est the stability of a ship is done by using several assumptions, namely:

a. The ship is in condition trim even keel;

b. The ship is in condition stable equilibrium;

c. The ship is in condition waterproof.
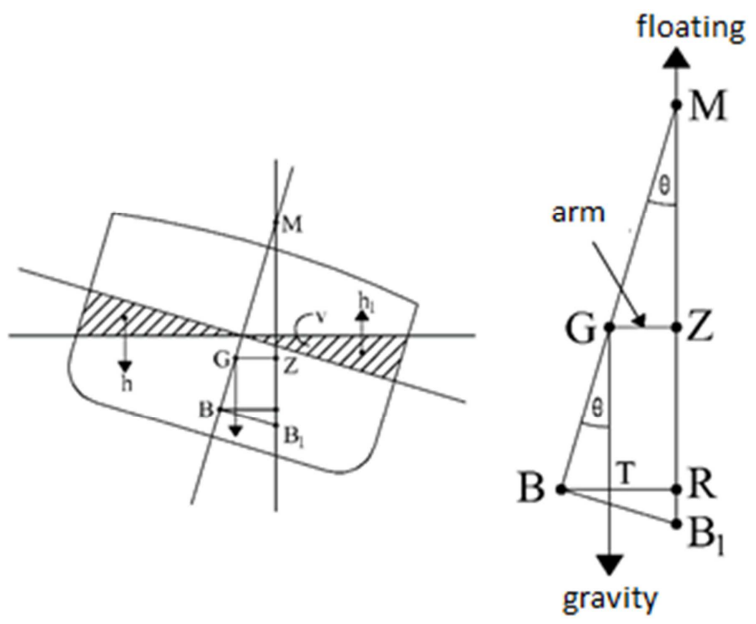

Source: Hind (1982)

Figure 3. Stability at ship angle.

In principle, the value of GZ can be determined using the following approach:

$$
\mathrm{GZ}=\mathrm{BR}-\mathrm{BT}
$$

The value of BR and BT is obtained by the equation:

$$
\begin{aligned}
\mathrm{BR} & =\frac{\square \times h h_{1}}{\nabla} \\
\mathrm{BT} & =\mathrm{BG} \sin \theta
\end{aligned}
$$

With to:

$\mathrm{GZ}=$ Backing arm

$\mathrm{BR}=$ Horizontal floating force center point

? $=$ Volume of ship in slices

$$
\mathrm{S}=L_{w l}(2 d+B) \sqrt{C_{\otimes}}\left(0,453+0,4425 C_{b}-0,2862 C_{\otimes}-0,003667 \frac{B}{d}+0,3696 C_{w}\right)+2,38 \frac{A_{B T}}{C_{b}}
$$

With to:

$\mathrm{S}=$ Wetted surface area $\left(\mathrm{m}^{2}\right)$

$\mathrm{L}_{\mathrm{wl}}=$ Length water line $(\mathrm{m})$

$\mathrm{A}_{\mathrm{BT}}=$ Bulb area, if the ship does not have a bulbous bow then $\mathrm{A}_{\mathrm{bT}}=0$

The value of the Frictional resistance coefficient is obtained using the following equation:

$$
\mathrm{C}_{\mathrm{f}=}=\frac{0,075}{\left(\log R_{n}-2\right)^{2}}
$$

With to:

$C_{f}=$ Frictional resistance coefficient

$\mathrm{Rn}=$ Reynold's number

\section{$\mathrm{hh}_{1}=$ Displacement of slices}

\subsubsection{Rolling Period}

Vessel rolling period data is processed using numerical methods he value of the ship's shaking period is obtained by using the formula (TR) or the rolling period of the ship's Intact Stability book by the International Maritime Organization (IMO), namely:

$$
\mathrm{T}_{\mathrm{R}}=\frac{2 \times \mathrm{C} \times \mathrm{B}}{\sqrt{\mathrm{GM}}}
$$

With to:

$\mathrm{T}_{\mathrm{R}}=$ rolling period

$$
\mathrm{C}=0,373+\left(0,023 \frac{\mathrm{B}}{\mathrm{T}}\right)-\left(0,043 \frac{\mathrm{Lwl}}{100}\right)
$$

$$
\begin{aligned}
& B=\text { Depth ship } \\
& T=\text { Draft ship } \\
& \text { LWL=Length water line } \\
& G M=\text { High of metacenter }
\end{aligned}
$$

\subsubsection{Resistance of Hull}

Resistance of hull are total resistance that arise due to the influence of the shape on the part of the ship's underwater boat [15] he value resistance of hull on a ship is done using numerical simulations he data needed to get the size of the ship's is the main dimensions, coefficient of fineness, and longitudinal center of bouyancy (LCB) urthermore, the data is processed using mathematical equations according to [16], namely:

$$
\mathrm{Rt}=\frac{1}{2} \rho V^{2} S\left\{C_{f}\left(1+k_{1}\right)\right\}
$$

With to:

$\mathrm{Rt}=$ Total frictional resistance $(\mathrm{N})$

The equation above shows that the value of wetted surface area $(\mathrm{S})$, frictional resistance coefficient $(\mathrm{Cf})$, and hull form factor $(1+\mathrm{k} 1)$ is needed to get the amount of cascade resistance arge values of wetted surface area are obtained using the following equation: design using the approach formula contained in the Code On

Reynold's number value is needed to get the value of the Frictional resistance coefficient he Reynold's number value is obtained using the following equation:

$$
\mathrm{Rn}=\frac{\mathrm{V} x L w l}{\mathrm{U}}
$$

with:

$$
\begin{aligned}
& \mathrm{V}=\text { Ship speed }(\mathrm{m} / \mathrm{s}) \\
& \mathrm{U}=\text { Kinematic Viscosity }
\end{aligned}
$$

Furthermore, the value of the hull form factor is obtained using the Holtrop equation as follows:

$$
1+\mathrm{k}_{1}=0,93+0,487118 \mathrm{C}
$$




$$
\begin{gathered}
\left(\frac{B}{L w l}\right)^{1,06806}\left(\frac{d}{L w l}\right)^{0,46106}\left(\frac{L w l}{L_{R}}\right)^{0,121563}\left(\frac{L w l^{3}}{\nabla}\right)^{0,36486} \\
\left(1-C_{p}\right)^{-0,604247}
\end{gathered}
$$

With to:

$1+\mathrm{k}_{1}=$ Hull form factor

$L_{R}=$ Length of the ship for the calculation of hull resistance (m)

$C=1+0,011 \mathrm{C}_{\text {stern }}$

$\mathrm{C}_{\text {stern }}=0$ (for common ship shapes)

Great Value $L_{R}$ needed to get the value of the hull factor using the following equation:

$$
\mathrm{L}_{\mathrm{R}=} \mathrm{L}_{\mathrm{wl}}\left\{1-C_{p}+0,06 C_{p}\left(\frac{L C B}{4 C_{p}-1}\right)\right\}
$$

With to:

$$
\mathrm{LCB}=\text { Longitudinal centre of bouyancy }(\mathrm{m})
$$

\subsection{Data Analysis}

Data analysis was performed to achieve the objectives of the study by using numerical comparative analysis o analyze stability, the GZ curve is used to compare with reference values he GZ curve is a ship stability curve that shows the maximum $\mathrm{GZ}$ value, the $\mathrm{GZ}$ value at each slope angle of the ship, the angle of attainment of GM (metacentre height) he GZ curve of the sampled vessel will be compared with the stability parameter values according to IMO code A. 749 (18) Ch 3 he static stability criteria based on [17] are shown as follows:

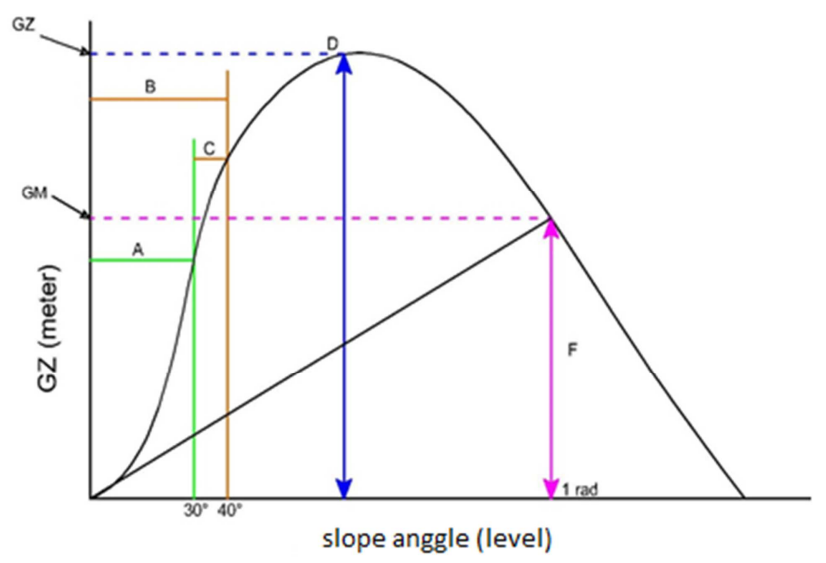

Figure 4. Stability curve.

Information:

a) The area under the static stability curve up to the sloping angle of $30^{\circ}$ must not be less than 0.055 radians;

B. The area under the static stability curve to the sloping angle of $40^{\circ}$ must not be less than 0.09 radians meters;

C. The area between the sloping angle of $30^{\circ}$ to $40^{\circ}$ must not be less than 0.03 meters radians, where the room on the deck will sink with the slab angle;
D. The maximum value of GZ should be reached at an angle of not less than $30^{\circ}$ and a minimum of 0.20 meters; Sudut maksimum stabilitas sebaiknya lebih dari $25^{\circ}$;

E. GM initial value should not be less than 0.15 meters.

Furthermore, the value of the rolling period of the ship is analyzed by comparing it to the reference rolling period amount based on the determination of [18] ccording to the reference, the rolling period value of a ship should be at 4.5 to 7 seconds.

\section{Results}

\subsection{The Main Dimension of Fishing Vessels in Kendari}

Handlines ships in Kendari have very diverse main dimensions ased on 32 units of measured handlines, there are three groups of vessels that have different class intervals, namely small, medium and large vessels he results of grouping ship handlines based on the main dimensions of the ship are presented in Table 1 able 1 shows that the category of large ship groups has a length (LOA) of vessels of $27.40 \mathrm{~m}$ to $28.41 \mathrm{~m}$, with an average length of $27.95 \mathrm{~m}$ he category of large ships group has a width (B) of ships from $3.41 \mathrm{~m}$ to $4.31 \mathrm{~m}$, with an average value of $3.91 \mathrm{~m} \mathrm{n}$ addition, the size of the ship height (D) has a value ranging from $1.22 \mathrm{~m}$ to $1.31 \mathrm{~m}$ with an average value of $1.27 \mathrm{~m} / \mathrm{B}$ values in large vessels have a range of values of 6.59-8.11 with an average value of 7.23 , L/D values ranging from $8.39-8.72$ with an average value of 8,56 and $\mathrm{B} / \mathrm{D}$ values ranging from 1.05 to 1.31 with an average value of 1.19 .

Vessels with medium category have a length (LOA) of vessels from $11.20 \mathrm{~m}$ to $17.95 \mathrm{~m}$, with an average length value of $14.33 \mathrm{~m} \mathrm{n}$ addition, ships in this category have a width (B) of ships ranging from $2.50 \mathrm{~m}$ to $3.50 \mathrm{~m}$, with an average value of $3.01 \mathrm{~m}$ wide $\mathrm{n}$ addition, large ship height (D) has a value ranging from $0.95 \mathrm{~m}$ to $1.21 \mathrm{~m}$ with an average value of 1.08 $\mathrm{m}$ urthermore, the comparison of the main dimensions in the medium group has a L/B range value of 4.27-5.19 with an average value of 4.72 , an $\mathrm{L} / \mathrm{D}$ value ranging from 10.48 15.36 with an average value average of 13.13 and $B / D$ values ranging from 2.61 to 3.09 with an average value of 2.77 .

The category of small vessels group has a length (LOA) of vessels of $8.65 \mathrm{~m}$ to $11.12 \mathrm{~m}$, with an average length value of $10.23 \mathrm{~m} \mathrm{n}$ addition, ships in this category have a width (B) of ships ranging from $1.90 \mathrm{~m}$ to $3.08 \mathrm{~m}$, with an average value of $2.45 \mathrm{~m} \mathrm{n}$ addition, large ship height (D) has values ranging from $0.95 \mathrm{~m}$ to $1.30 \mathrm{~m}$ with an average value of $1.13 \mathrm{~m}$ urthermore, the comparison of the main dimensions in the medium ship group has a range of L/B values of 3.61-4.74 with an average value of 4.24 , an $\mathrm{L} / \mathrm{D}$ value ranging from 8.54-10.00 with an average value average of 9.12 and $B / D$ values ranging from 1.86 to 2.36 with an average value of 2.17 . 
Table 1. The main dimension of the handline ship is Kendari.

\begin{tabular}{|c|c|c|c|c|c|c|c|c|}
\hline No & Name Ships & $\mathbf{L}_{\mathrm{OA}}$ & $\mathbf{B}_{\max }$ & Depth & Item & $\mathbf{L} / \mathbf{B}$ & $\mathbf{L} / \mathbf{D}$ & B/D \\
\hline 1 & KM.JAYA & 27,40 & 3,45 & 1,22 & \multirow{10}{*}{ BIG } & 7,94 & 22,46 & 2,83 \\
\hline 2 & KM.ANUGRAH 05 & 27,45 & 3,49 & 1,27 & & 7,87 & 21,61 & 2,75 \\
\hline 3 & KM.ANUGRAH 07 & 27,65 & 3,41 & 1,26 & & 8,11 & 21,94 & 2,71 \\
\hline 4 & KM.BERKAT & 27,76 & 3,48 & 1,31 & & 7,98 & 21,19 & 2,66 \\
\hline 5 & KM.KENDARI 01 & 27,87 & 4,05 & 1,26 & & 6,88 & 22,12 & 3,21 \\
\hline 6 & KM.UJUNG LERO & 28,05 & 4,20 & 1,27 & & 6,68 & 22,09 & 3,31 \\
\hline 7 & KM.SINAR MAS & 28,21 & 4,21 & 1,29 & & 6,70 & 21,87 & 3,26 \\
\hline 8 & KM.BERKAH SAMUDRA 07 & 28,31 & 4,23 & 1,25 & & 6,69 & 22,65 & 3,38 \\
\hline 9 & KM.FADILLAH 77 & 28,34 & 4,25 & 1,25 & & 6,67 & 22,67 & 3,40 \\
\hline \multirow[t]{2}{*}{10} & KM.EMJ LIMA & 28,41 & 4,31 & 1,28 & & 6,59 & 22,20 & 3,37 \\
\hline & Average: & 27,95 & 3,91 & 1,27 & \multirow[t]{6}{*}{ Average: } & 7,23 & 22,06 & 3,08 \\
\hline 11 & KM.SINAR SAMUDRA & 11,20 & 2,50 & 0,95 & & 4,48 & 11,79 & 2,63 \\
\hline 12 & KM.SINAR SAMUDRA 05 & 11,25 & 2,62 & 0,95 & & 4,29 & 11,84 & 2,76 \\
\hline 13 & KM.FATMA JAYA 01 & 11,29 & 2,63 & 0,98 & & 4,29 & 11,52 & 2,68 \\
\hline 14 & KM.FATMA JAYA 02 & 11,32 & 2,65 & 1,08 & & 4,27 & 10,48 & 2,45 \\
\hline 15 & KM.FATMA JAYA 03 & 12,52 & 2,85 & 1,09 & & 4,39 & 11,49 & 2,61 \\
\hline 16 & KM.JAYA UTAMA & 14,25 & 2,96 & 1,08 & \multirow[t]{6}{*}{ MIDDLE } & 4,81 & 13,19 & 2,74 \\
\hline 17 & KM.PUTRA SINJAY & 15,12 & 3,06 & 1,08 & & 4,94 & 14,00 & 2,83 \\
\hline 18 & KM.CARI MUATAN 09 & 16,9 & 3,40 & 1,10 & & 4,97 & 15,36 & 3,09 \\
\hline 19 & KM.SINAR JAYA 06 & 17,9 & 3,45 & 1,19 & & 5,19 & 15,04 & 2,90 \\
\hline 20 & KM.SINAR JAYA 07 & 17,91 & 3,50 & 1,20 & & 5,12 & 14,93 & 2,92 \\
\hline \multirow[t]{2}{*}{21} & KM.SINAR JAYA 08 & 17,95 & 3,49 & 1,21 & & 5,14 & 14,83 & 2,88 \\
\hline & Average: & 14,33 & 3,01 & 1,08 & \multirow[t]{6}{*}{ Average: } & 4,72 & 13,13 & 2,77 \\
\hline 22 & KM.DOA HIDAYAH & 14,65 & 2,90 & 1,30 & & 4,55 & 9,11 & 2,00 \\
\hline 23 & KM.NUR ALIYA SAFITRI & 14,67 & 2,95 & 1,31 & & 4,13 & 9,13 & 2,21 \\
\hline 24 & KM.RIAN UTAMA & 14,70 & 3,03 & 1,29 & & 4,43 & 10,00 & 2,26 \\
\hline 25 & KM.RITA JAYA 02 & 14,76 & 3,03 & 1,32 & & 4,28 & 9,96 & 2,33 \\
\hline 26 & KM.DUA PUTERA & 14,87 & 3,00 & 1,35 & & 4,29 & 9,97 & 2,32 \\
\hline 27 & KM.MANDIRI JAYA & 14,90 & 3,12 & 1,33 & \multirow[t]{6}{*}{ SMALL } & 4,74 & 8,86 & 1,87 \\
\hline 28 & KM.KENDARI MAJU & 14,92 & 3,15 & 1,25 & & 4,73 & 8,81 & 1,86 \\
\hline 29 & KM.KONAWE PUTRA & 14,95 & 3,14 & 1,28 & & 4,56 & 8,83 & 1,94 \\
\hline 30 & KM.CAKALANG & 15,00 & 3,00 & 1,30 & & 3,67 & 8,59 & 2,34 \\
\hline 31 & KM.KOLAKA MAKMUR & 15,02 & 3,15 & 1,29 & & 3,61 & 8,54 & 2,36 \\
\hline \multirow[t]{2}{*}{32} & KM.BUTON & 15,12 & 3,18 & 1,34 & & 3,61 & 8,55 & 2,37 \\
\hline & Average: & 10,23 & 2,45 & 1,13 & Average: & 4,24 & 9,12 & 2,17 \\
\hline
\end{tabular}

Based on Table 1, the ratio of $\mathrm{L} / \mathrm{B}$ values in the medium ship category and small ship category compared to ships in the large ship category /B values in medium and small ship groups have mutually overlapping values his shows that ships in the medium and small groups both have a fatter hull compared to large ship groups his can be understood considering the handline ship is included in the passive fishing gear so that the preferred aspect is not the speed of the ship but stability, hatch capacity and work space on the ship owever, based on the results of the study of [19], the L/B ratio which ranges from the value of 4.20 is included in the group of lean ships so that the friction area in the hull will be of little value his will have a positive impact on ship speed.

Large ship groups have a greater $\mathrm{L} / \mathrm{B}$ range his shows that ships with a large group category have a leaner ship body so that it will provide a smaller resistance value his is in accordance with a study conducted by [20] that the smaller the value of $\mathrm{L} / \mathrm{B}$, the ship has good movement but causes slowing speed his happens because with the smaller value of the $\mathrm{L} / \mathrm{B}$ ratio of the ship, it will provide greater resistance so that the resulting ship resistance will be greater so that it will negatively impact the speed of the ship [21].

Table 1 shows that the L/D ratio values of large and small vessels have not much different values his is different from the L/D comparison value produced by medium-sized ship groups with a greater value than large groups and small ship groups ccording to the value of the comparison between the length and height of the ship shows the elongated strength of a ship he greater the value of the $\mathrm{L} / \mathrm{D}$ ratio will result in the ability to lengthen the ship will be increasingly weakened [22] his shows that the group of ships is having the ability to elongate ships which is worse than the large and small ships group his happens because the length is not proportional to the size in it ccording to [23] the lengthening force of a ship is needed so that the ship remains strong despite facing high wave conditions when conducting fishing operations in fishing areas ased on Table 1, the ratio of width and height $(\mathrm{B} / \mathrm{D})$ of the ship shows the value that varies in each group of ships he $\mathrm{B} / \mathrm{D}$ value of the ship is used to define the ability of stability and also the ability to drive the ship [24] n sequence, the largest $\mathrm{B} / \mathrm{D}$ ratio values are generated by the medium ship group, followed by the small and large ship group ccording to $[25]$ the smaller the $B / D$ value, the stability of the ship will worsen, but the ability of the ship's propulsion will be better his shows that the medium group of ships has the best stability ability compared to the small and large group of ships.

The results of the comparison of the main dimensions of the three ship groups show that when compared with the operation of handlines fishing gear, a vessel with good 
stability, fish hatch capacity and work area is needed his happens because the ship's handlines fall into the category of fishing gear that is operated passively so that the more needed aspect is the aspect of high stability compared to the aspects of speed, resistance, and turning ability of the ship [26] herefore, based on the comparison of the main dimensions, medium size ships have more qualified criteria compared to large and small vessels his is because the group of ships is having a smaller $\mathrm{L} / \mathrm{B}$ ratio and the biggest $\mathrm{B} / \mathrm{D}$ so that it has a better stability capability.

\subsection{Stern Bow}

Based on field observations the shape of the bow height owned by the Handlines has the shape of a raked bow as shown in Figure 5 addition, the large angle of inclination of each vessel used as a sample is shown in Figure 5.

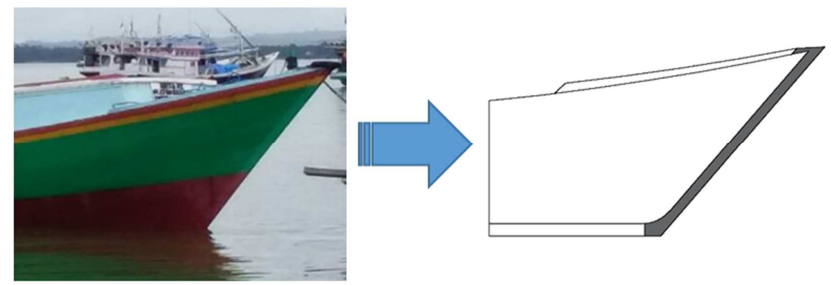

Figure 5. The shape of the curved dial raked bow.

Figure 6 shows that there are various head-to-head slopes on the Kendari handlines owever, if grouped by ship size group, the tilt of the bow in each group of ships has uniformity arge vessels have a high tilt of the course that ranges from $62^{\circ}$ to $70^{\circ}$ so that the average slope is $65.4^{\circ}$ his is indicated by $\mathrm{KM}$ MJ Lima to KM aya urthermore, the group of ships is showing a smaller tilt of the bow, which ranges from $55^{\circ}$ to $61^{\circ}$ with an average high tilt of $57.64^{\circ}$ which is indicated on the KM ship inar Jaya 08 to KM inar Samudera he slope of the small ship group has a smaller angle, which is between $45^{\circ}$ to $55^{\circ}$ and the average tilt of the bow is $49.81^{\circ}$ mall boat groups are shown in $\mathrm{KM}$ uton to $\mathrm{KM}$ idayah prayer llustration of bow height on each group of vessels is shown in Figure 6.

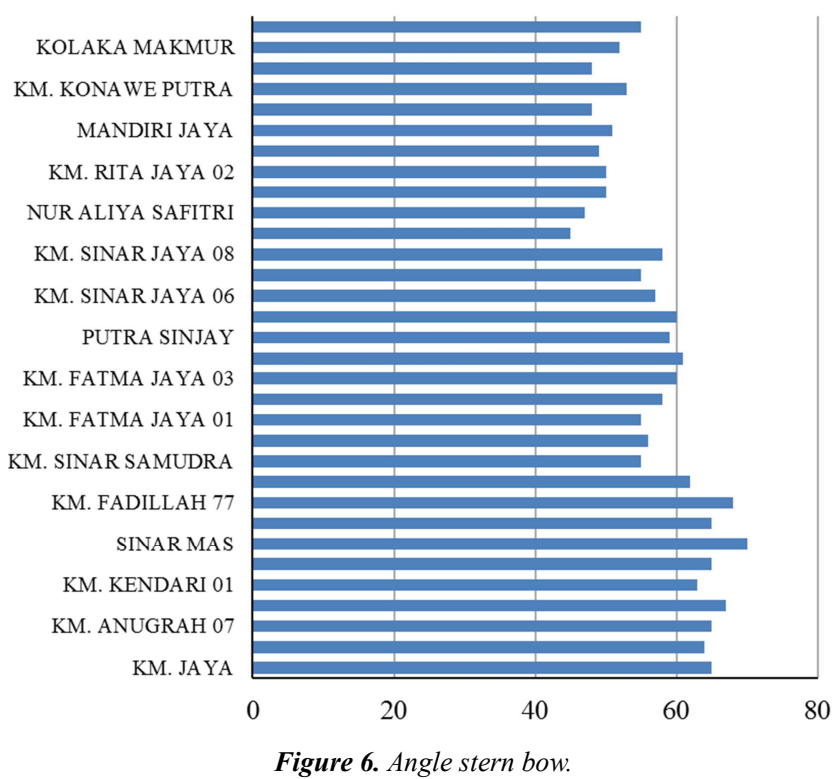

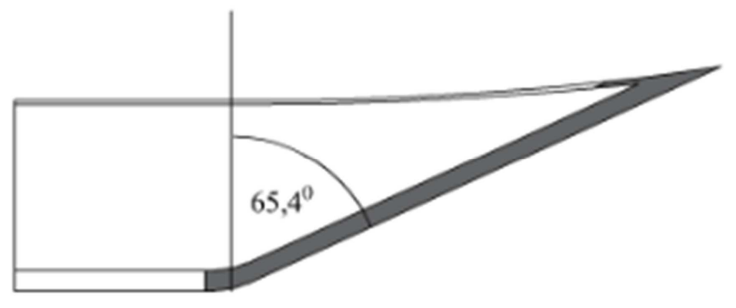

(a) Kelompok kapal besar

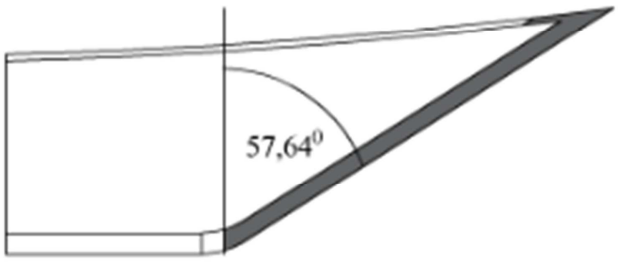

(b) Kelompok kapal sedang

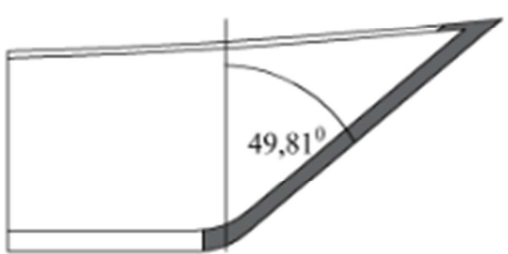

(c) Kelompok kapal kecil

Figure 7. The average slope of the stern bow.

Based on Figure 7, the bow height of the three ship groups in the Kendari region has a slope angle of more than $45^{\circ}$ ased on the results of the study of [3] there are two bow-high tilt groups in Indonesia, namely the groups below and above $45^{\circ}$ or raked bow ramps and vertical raked bow herefore, handline vessels in the Kendari region are included in the raked bow ramps $\mathrm{n}$ addition, if related to the main dimensions of the ship, ships in the Kendari region with a raked bow height have a $\mathrm{L} / \mathrm{D}$ ratio in accordance with the study of [3] his shows that the shape of the bow height of raked bow ramps is a form that is often used after the raked bow is upright and is used by ships with varying length and 
height dimensions he relationship of $\mathrm{L} / \mathrm{D}$ to the shape of the bow height because the bow height is one part of ship construction that supports the lengthening force of the ship [27] he variation in the bow height of this ship occurs because the construction of this type of ship is carried out in two different places, namely in the Kendari region and the Buton Island region.

\subsection{Shape of the Hull}

The shape of the hull provides a broad influence on the design character tudy of the shape of the ship body is carried out on the cross section shape of the ship Kasko transervsal $n$ addition, the shape of the ship's body also affects the motion resistance, performance, hatch capacity, work space on the deck and the stability of the ship ccording to [2] there are five types of boat kasko forms in Indonesia, namely round bottom, flat bottom, u-bottom, akatsuki bottom and hard chin bottom ased on observations, there are differences in the forms of cross section of the ship Kasko in the three groups of ships, namely small, medium, large groups he three forms of cross section of the kasko are presented in Figure 8.

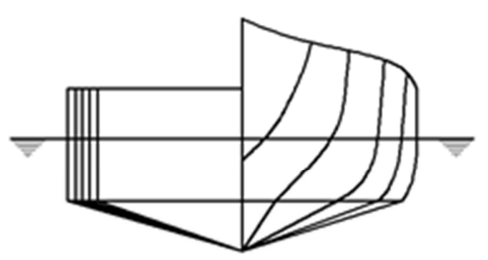

(a) Class intervals small

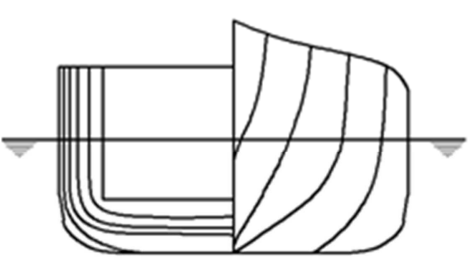

(b) Class intervals medium

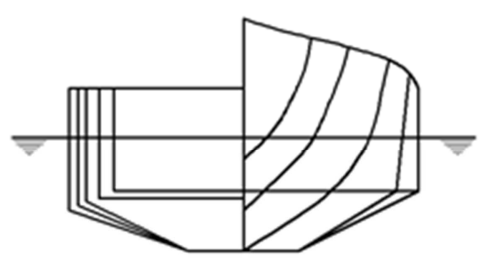

(c) Class intervals large

Figure 8. Transverse shape.

Figure 8 shows the shape of a Kasko cross section based on a body plan in the center of the ship ased on Figure 8 a, the cross section of a large group of vessels is included in the hard bottom urthermore, the shape of the ship's kasko section with a medium size category based on the line at the center of the ship appears transversely, showing the shape of the ubottom kasko (Figure 8 b) n addition, the shape of the kasko The shape of the hull with a small size category based on the line at the center of the ship appears transversely, showing the shape of the kasats akatsuki (Figure $8 \mathrm{c}$ ).

Different forms of cross section of a ship will certainly affect the performance of the ship's movement itself ccording to [2] ships in the form of boat casko such as u-bottom and akatsuki bottom tend to have a higher stability ability compared to other boat kasko owever, when viewed from the ability to exercise, the two forms of kasko have a lower ability than other forms of kasko rom the two forms of the ship's kasko the akatsuki bottom has better movement ability than the u-bottom shape.

The use of u-bottom shape on the dimensions of the width and height of the same ship will produce a hatch capacity that is greater than the other boat kasko shapes (such as round bottom and round flat bottom) asko U-bottom form, is the ideal form for ships that operate fishing gear statically [4] his is because the ship's u-bottom has a high stability ability his is also supported by the results of a study conducted by [28] that for ships operating fishing gear that do not prioritize speed in operation (handline, longline, gillnet and trap and so on), the U-bottom and Akatsuki forms are suitable for use.
The cross section of a ship with a hard chin as used in large group ships has different performance from medium and small ship groups ased on the results of the study of [2] hard chin form has a fairly good ability to exercise owever, this form is estimated to have a higher rate of ability compared to other forms of kasko his is allegedly because resistance caused by such a form of kasko are smaller than other forms of kasko his is supported by studies conducted by [28] that the shape of hard chin kasko can provide speed in the process of arrest, this happens because with the form of kasko hard chin eat smaller resistance than U-bottom and akatsuki bottom ased on the results of the three forms of kasko shows that the use of fishing gear handlines is more suitable for use by the u-bottom form.

\subsection{Shape of Water Plan Area}

The shape of the water plan area is represented in the shape of the ship's deck as a whole he shape of this deck gives an illustration of whether the shape of ships in the Kendari region has a uniform or varied form ased on observations in the field there are differences in the shape of ships in the Kendari region, namely the form of transom and double pointed he shape of the transom is the elongated shape of the ship with the shape of its tapered head and the long stern of the beam $n$ contrast to the double pointed shape, according to [29] Panampang ship with a double pointed shape is a form of a ship with a left hull and right hull which meet at one point at the end of the bow and stern. 
The use of the two cross sections is also not balanced against the group shape based on the main dimensions ransom form is used on ships that are included in large and medium groups eanwhile, the double pointed shape is used on ships that fall into small groups he figure of the shape of the ship's water plan is presented in Figure 9 and Figure 10.

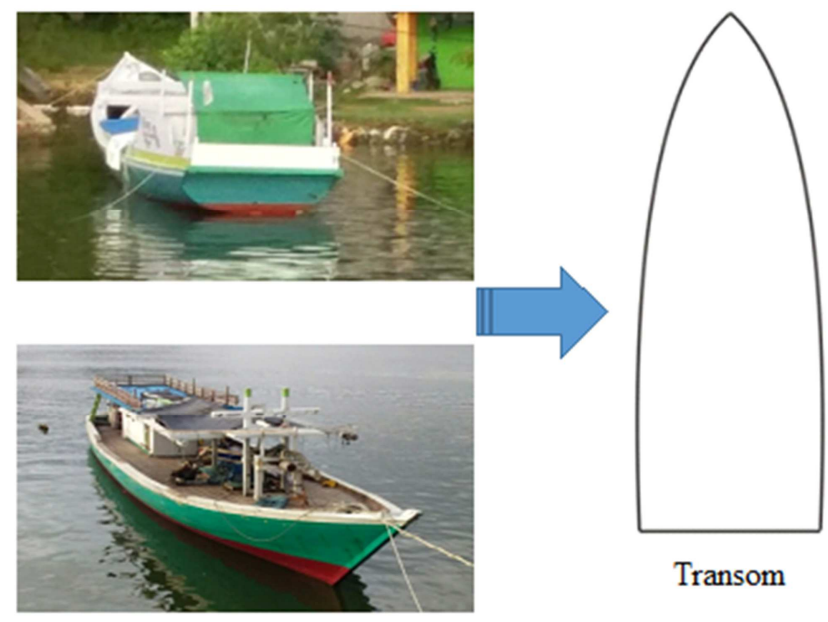

Figure 9. The shape of the transom.
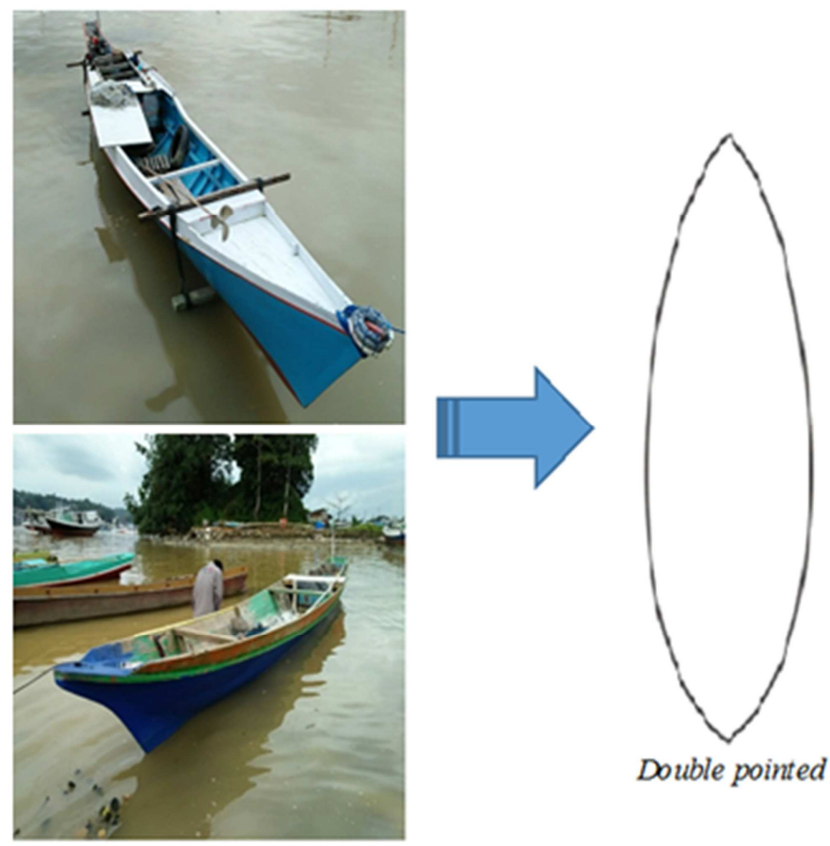

Figure 10. Shape of the ship from the top.

Based on Figures 9 and 10, the difference between the two cross sections is seen from the stern shape lthough the shape of the stern of the ship does not significantly influence the performance and stability of the ship, the shape of the stern is closely related to the effectiveness of the rudder leaf in controlling the direction of the ship he difference occurs when ship building is done as in the form of double pointed he double pointed ship was built by traditional shipyards around Kendari and Buton Island, which are generally dominated by shipbuilders from Bugis origin or ships with large and medium size categories all have a transom hereas the double pointed shape is only found on ships with small size categories.

The double pointed shape is only found on ships with small size categories hips with a double-pointed deck are built by traditional shipyards around Kendari and Buton Island, which are generally dominated by shipbuilders from Bugis origin $n$ addition, each shipyard has not yet set the bow height range so that although it is built in the same shipyard, the variation of the bow height is quite high.

Although the shape of the stern of the ship does not significantly influence the performance and stability of the ship, the shape of the stern is closely related to the effectiveness of the rudder leaf in controlling the direction of the ship he stern shape of the ships in all three class intervals can be grouped into two types he first group is ships with a stern shape that is similar to the bow/tilt shape of the ship he second group is ships with a stern shape that is different from flat boat bow shapes [3] he difference in the shape of the stern is generally related to the use of the type of machine (external engine or inner engine), work space requirements and the customs of the shipyard in fishing boat manufacturing.

\subsection{Main Deck House}

Small vessels or class 3 hoses generally do not have permanent buildings on deck he duration of the fishing trip which is only one day with a short length of time at sea causes fishermen to build semi-permanent buildings from bamboo and tarpaulins to protect the work area eanwhile, medium sized vessels in class 2 hose or large vessels in class 1 hose have buildings on deck due to longer trip times or the operation of medium-sized vessels at class 2 interval requires operating time of 2-3 days per trip s for the operation of large vessels in class 1 interval, it takes about 5-7 days per trip esides being used as a fisherman's accommodation room and supplies, the building on the deck also serves to protect the ship's engine from rain and sun's heat $n$ general, the type of building on the deck can be divided into two groups based on their position towards midship he first type is the building behind the ship midship and the second type is in the middle of the ship's midship.

The position of the building on the deck is generally made to adjust to the space requirements and demands of the ship owner here are no specific criteria used by shipbuilders in traditional shipyards to determine the shape, size and position of buildings that are made he habit and knowledge factor is hereditary or commonly referred to as local wisdom which is the basis for determining dimensions and specifications, as shown in Figure 11. 

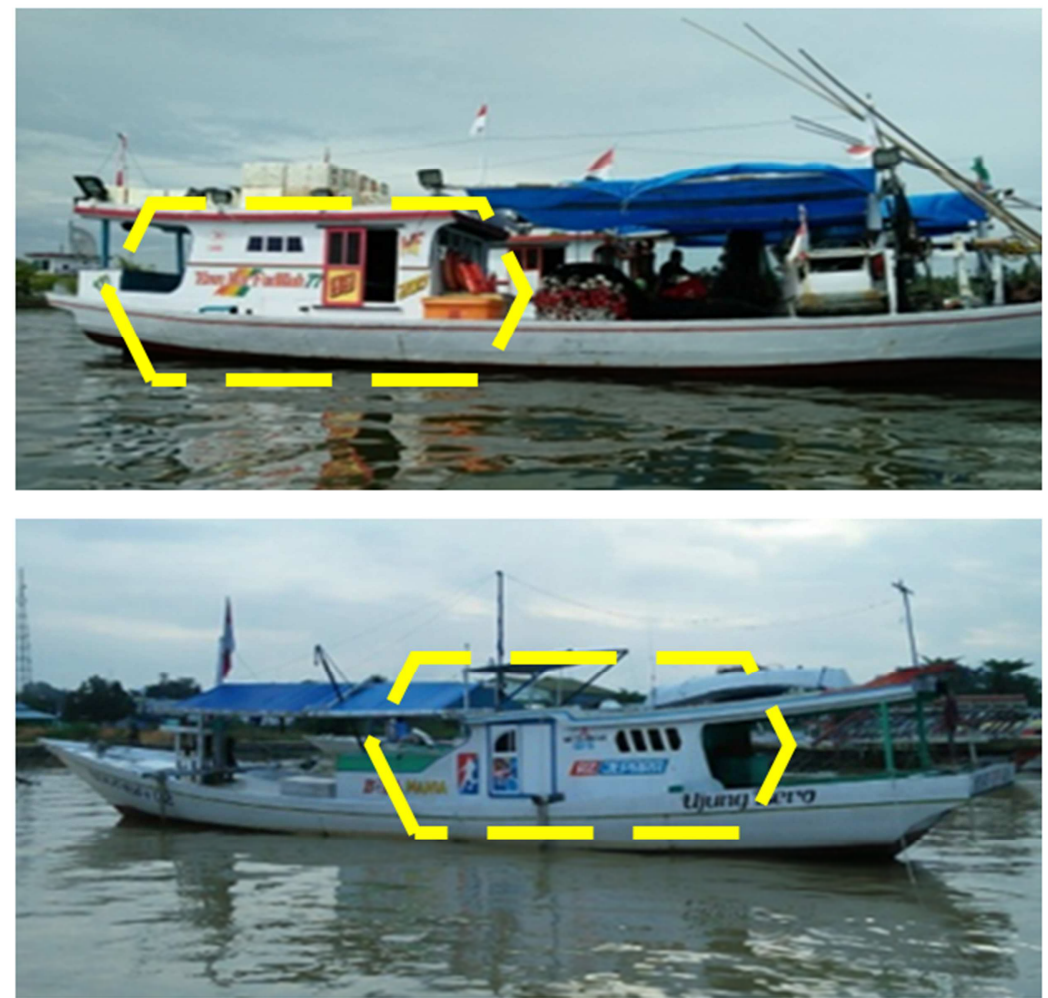

Figure 11. Main deck house fishing boat in Kendari.

\section{Discussion}

\subsection{Technical Study of Handline Ships in Kendari}

A technical feasibility study was carried out on each group of ships in the Kendari area, namely large, medium and small group handline vessels he sample vessels are one ship of each type and with a dominant length.

Referring to the field results, there were 100 fishing vessels in the location obtained, then 32 boats using handline fishing gear were taken and operated using handline fishing gear urthermore, vessel dimension data is processed to obtain the ratio of the main dimensions consisting of $\mathrm{L} / \mathrm{B}, \mathrm{L} / \mathrm{D}$ and $\mathrm{B} / \mathrm{D}$.

Of the 32 units of ships divided into 3 groups, namely large groups of 10 units of ships, medium groups of 11 units of ships and small groups of 11 units of ships rom each class group $10 \%$ are taken, so 1 unit of each ship is made a Lines Plan as shown in Figures 12, 13 and 14.

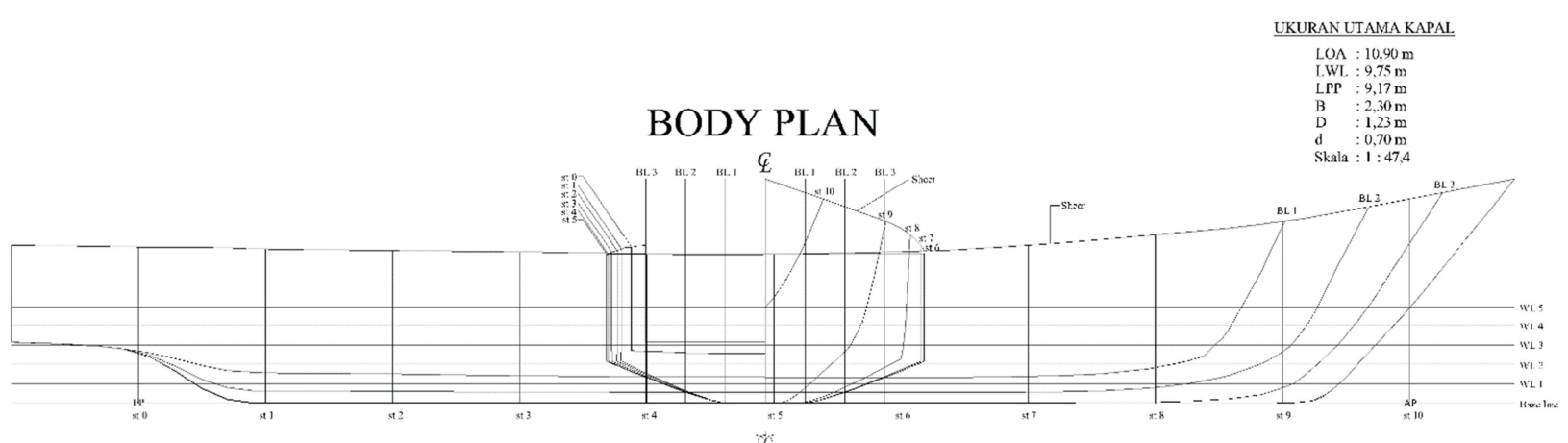

PROFILE PLAN

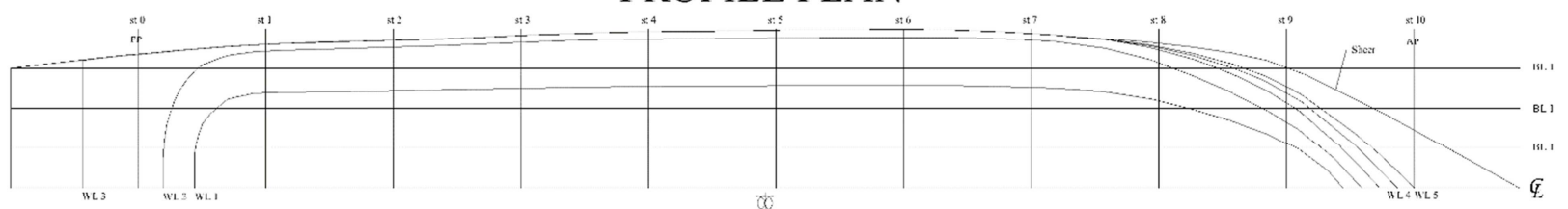

HALF BREADTH PLAN

Figure 12. Lines plan ship class of small. 


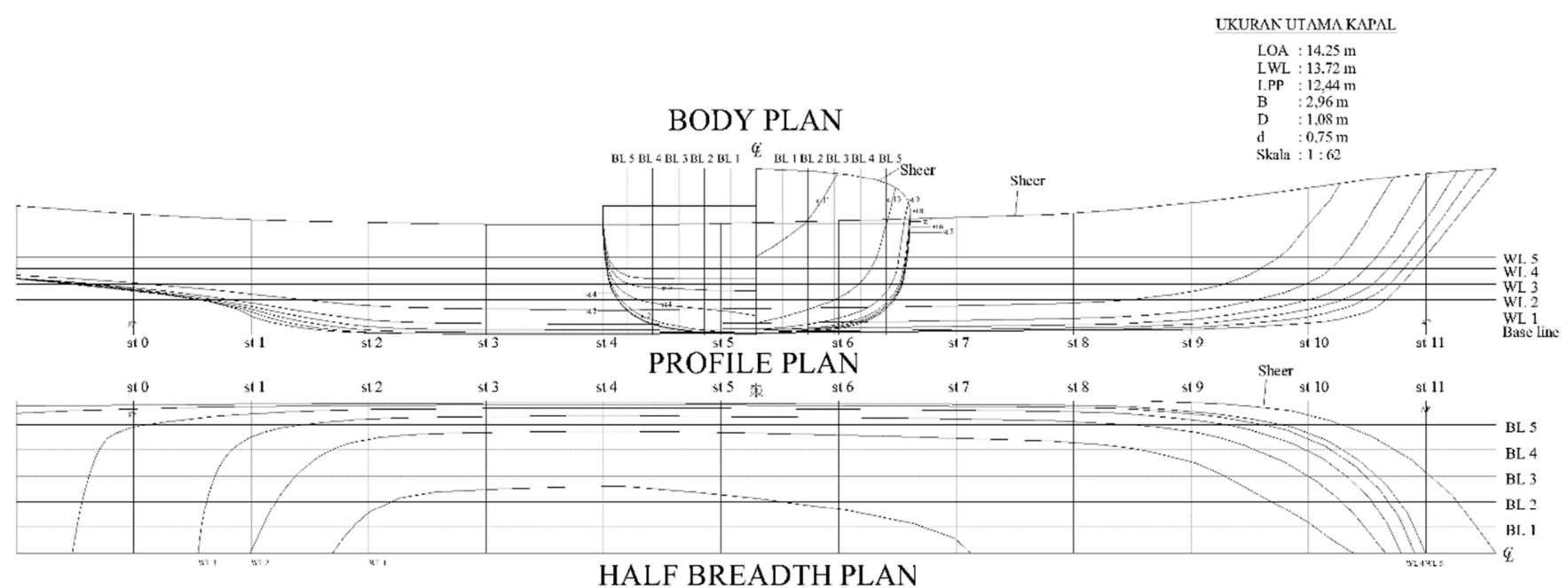

Figure 13. Lines plan ship class of medium

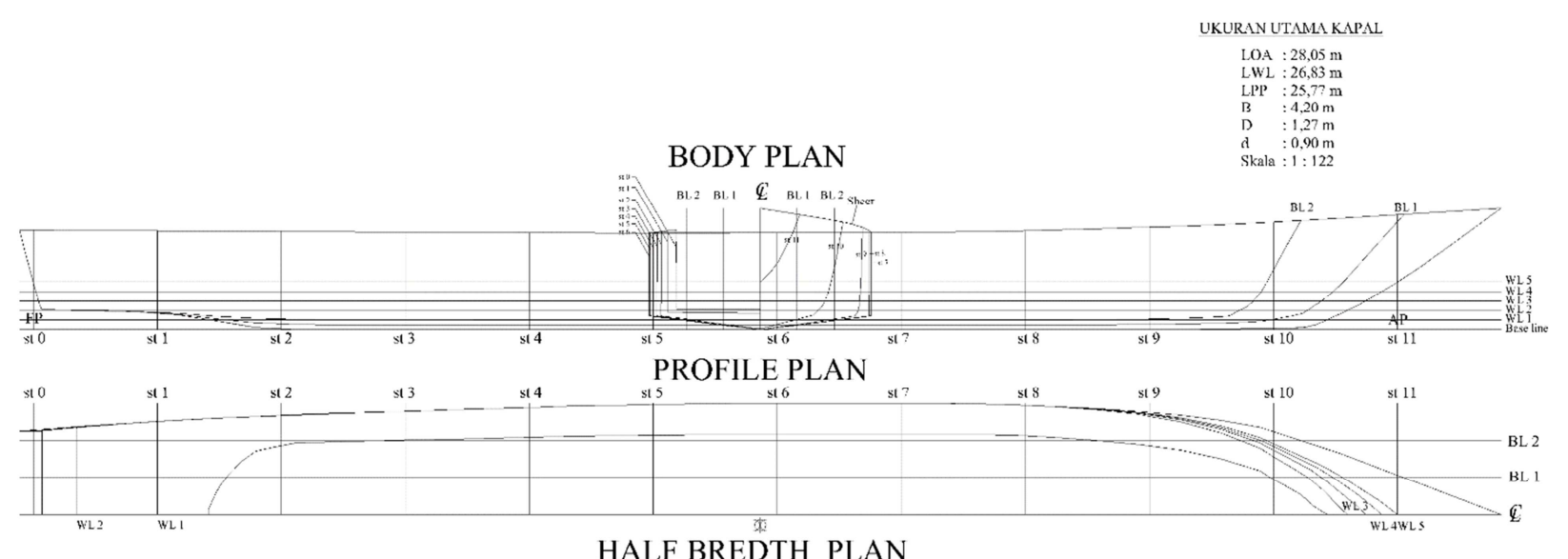

HALF BREDTH PLAN

Figure 14. Lines plan ship class of large.

Based on the three images above, the hydrostatic parameter calculation results obtained on the three handline vessels in Kendari are shown in Table 2.

Table 2. Hydrostatic parameters of handline vessels in Kendari.

\begin{tabular}{llll}
\hline \multirow{2}{*}{ Parameter } & Clasification & Medium & Small \\
\cline { 2 - 4 } & Large & 20,41 & 11,07 \\
\hline Volume Displacement $(\mathbf{\nabla})\left(\mathrm{m}^{3}\right)$ & 69,41 & 20,92 & 11,35 \\
Ton Displecement $(\mathbf{\Lambda})($ ton $)$ & 71,14 & 37,34 & 20,17 \\
Water Area $(\mathrm{WPA})\left(\mathrm{m}^{2}\right)$ & 94,05 & 1,90 & 1,37 \\
Midship Area $(\mathrm{AÄ})\left(\mathrm{m}^{2}\right)$ & 3,27 & 0,69 & 0,68 \\
Coefficient of Block $(\mathrm{Cb})$ & 0,71 & 0,79 & 0,8 \\
Coefficient of Prismatic $(\mathrm{Cp})$ & 0,82 & 0,73 & 0,78 \\
Coefficient Vertical Prismatic $(\mathrm{Cvp})$ & 0,82 & 0,94 & 0,87 \\
Coefficient Waterplane $(\mathrm{Cw})$ & 0,88 & 0,87 & 0,85 \\
Coefficient Midship $(\mathrm{CÄ})$ & 0,86 & 0,91 & 0,38 \\
GM $(\mathrm{m})$ & 1,32 & & \\
\hline
\end{tabular}

Table 2 shows the formability and the coefficient of fineness of the three types of vessel groups in the Kendari area at maximum ship laden conditions ased on the volume value of the displacement, the large ship group has a greater value compared to the medium ship group, but has a vast difference from the small ship group his shows that large groups of vessels have larger capacity/volume of submerged bodies of water submerged compared to medium and small vessels.

The largest $\mathrm{Cb}$ value is generated by large ship groups, followed by medium ship groups and small ship groups his makes the large ship group have the fattest shape of the hull, but it is directly proportional to the results shown in volume displacement, ton displacement, waterplan area, and midship 
area he $\mathrm{Cb}$ value produced by medium and small ship groups has a smaller value, because the bow and stern parts of the hull have a very extreme change hips with a $\mathrm{Cb}$ value of around 0.5 are ships that have a transitional hull shape between fat ships (rounded) to slim (chine) $\mathrm{n}$ addition, this is also influenced by the shape of the ship's height which is included in the raked bow category hips that use raked bow height as in all ships, tend to have a greater coefficient of fineness compared to ships using other bow height [3].

The $\mathrm{Cp}$ value in the medium and small ship group is a smaller value compared to the large ship group ccording to [30], ships with a smaller Cp value exhibit smaller motion resistance, and ships with a $\mathrm{Cp}$ value of 0.6 are the fishing vessels that experience the minimum motion resistance mall prismatic coefficient values represent the magnitude of horizontal changes in the shape of the hull $\mathrm{n}$ the other hand, ships that undergo slight cross-section changes will have a large $C p$ value [31] $n$ addition, a large $C p$ value indicates that the longitudinal cross section of the ship both towards the bow and the stern will be the same as the longitudinal cross section of the ship's center his is reflected by showing the $\mathrm{Cp}$ value of medium and small ship groups that have smaller values compared to large ship groups so that it shows changes in the shape of the hull on the bow and extreme stern.

The largest Cvp value among the three ship groups is generated by large ship groups followed by small and medium ship groups large Cvp value will affect the value of the wave fraction, friction resistance and reduction in the thrust of the ship [32] herefore, the increasing value of Cvp then the three values will also increase $\mathrm{n}$ addition, the large value of $\mathrm{Cw}$ and $\mathrm{C} \otimes$ in the large ship group is the largest value followed by the value of the medium and small ship group his shows that the length of the longitudinal cross section and the shape of the hull in the midship section of the large ship group is greater than the medium and small ship groups.

\subsection{Stability}

The stability curves of the three vessel groups in the Kendari area under empty ship conditions and full load conditions are shown in Figures 15 and 16.

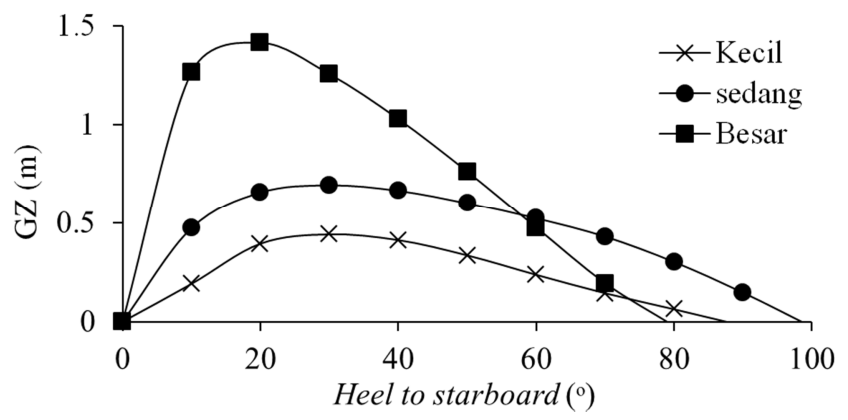

Figure 15. Handline ship stability curve in empty condition.

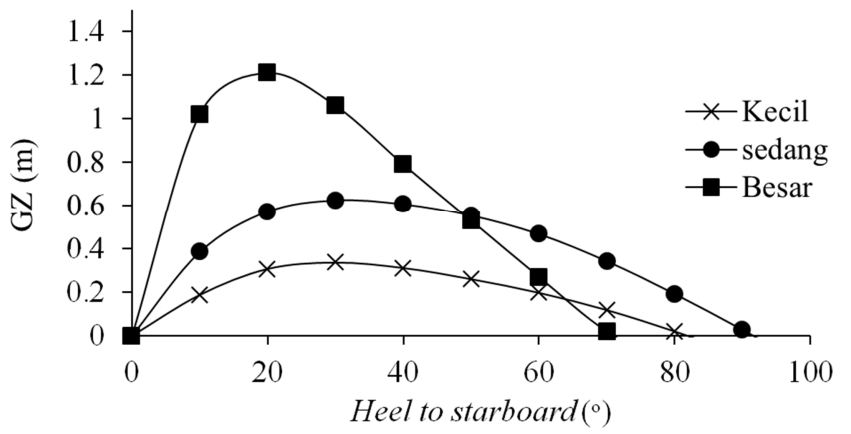

Figure 16. Handline ship stability curve at full load condition.

Figures 15 and 16 show that a large group of vessels having a length of GZ does not meet IMO recommendations because GZ max occurs less than 30 his is inversely proportional to the $\mathrm{L} / \mathrm{B}$ ratio on medium and small group vessels which results in smaller values so that medium and small vessels should have better stability his happens because medium and small vessels have larger freeboards compared to large vessels, thus adversely affecting the resulting stability arm ccording to [33] the smaller the ladder of the ship, the freeboard of the ship gets bigger so that the angle of the slope to the edge of the deck sinks into the water will also be even greater he width of the ship's waterline will be greater with increasing tilt angle to the tilt angle where the edge of the deck is immersed in water $\mathrm{s}$ a result of this phenomenon, the radius of the metacentra (MB) is getting bigger so that the stability arm is also getting bigger with the increase in the width and ladder ratio of the ship ven so, the maximum GZ angle generated on each ship shows a value that is not much different.

The results of comparison of IMO criteria on each ship and different cargo are shown in Tables 3, 4 and 5.

Table 3. Small group ship stability curve against IMO criteria.

\begin{tabular}{lllll}
\hline \multirow{2}{*}{ Kriteria } & IMO & \multicolumn{2}{l}{ Condition } & \multirow{2}{*}{ Result } \\
\cline { 3 - 4 } & & Empty & Full & \\
\hline $\mathrm{A}$ & $>0,055 \mathrm{~m} \mathrm{ad}$ & 8,205 & 6,793 & Fulfilled \\
$\mathrm{B}$ & $>0,09 \mathrm{~m} \mathrm{ad}$ & 12,518 & 10,056 & Fulfilled \\
$\mathrm{C}$ & $>0,03 \mathrm{~m} \mathrm{ad}$ & 4,313 & 3,263 & Fulfilled \\
$\mathrm{D}$ & $>0,2 \mathrm{~m}$ & 0,441 & 0,336 & Fulfilled \\
$\mathrm{E}$ & $>25^{\circ}$ & 30 & 29 & Fulfilled \\
$\mathrm{F}$ & $>0,15 \mathrm{~m}$ & 0,965 & 0,998 & Fulfilled \\
\hline
\end{tabular}

Table 4. Medium group vessel stability curves against IMO criteria.

\begin{tabular}{lllll}
\hline \multirow{2}{*}{ Kriteria } & \multirow{2}{*}{ IMO } & \multicolumn{2}{l}{ Condition } & \multirow{2}{*}{ Result } \\
\cline { 3 - 4 } & & Empty & Empty & \\
\hline A & $>0,055 \mathrm{~m} \mathrm{ad}$ & 15,187 & 13,026 & Fulfilled \\
B & $>0,09 \mathrm{~m} \mathrm{ad}$ & 22,021 & 19,224 & Fulfilled \\
C & $>0,03 \mathrm{~m} \mathrm{ad}$ & 6,833 & 6,198 & Fulfilled \\
D & $>0,2 \mathrm{~m}$ & 0,693 & 0,626 & Fulfilled \\
E & $>25^{\circ}$ & 30 & 32 & Fulfilled \\
F & $>0,15 \mathrm{~m}$ & 3,37 & 2,51 & Fulfilled \\
\hline
\end{tabular}


Table 5. Large group vessel stability curves against IMO criteria.

\begin{tabular}{lllll}
\hline \multirow{2}{*}{ Kriteria } & \multirow{2}{*}{ IMO } & \multicolumn{2}{l}{ Condition } & \multirow{2}{*}{ Result } \\
\cline { 3 - 4 } & & Empty & Empty & \\
\hline A & $>0,055 \mathrm{~m} \mathrm{ad}$ & 35,178 & 33,04 & Fulfilled \\
B & $>0,09 \mathrm{~m} \mathrm{ad}$ & 47,192 & 43,458 & Fulfilled \\
C & $>0,03 \mathrm{~m} \mathrm{ad}$ & 12,014 & 10,419 & Fulfilled \\
D & $>0,2 \mathrm{~m}$ & 1,305 & 1,165 & Fulfilled \\
E & $>25^{\circ}$ & 14,9 & 16 & - \\
F & $>0,15 \mathrm{~m}$ & 2,903 & 2,625 & Fulfilled \\
\hline
\end{tabular}

The value of stability produced on the three types of ships shows the value that matches the IMO criteria, where the stability conditions shown on medium and small group ships have a positive stability value on every condition of a full cargo ship positive GZ value indicates that the ship can return to its original position after the shaking, while a negative GZ value indicates that the ship does not have a return moment when the ship shakes [34].

The GM value generated by each type of ship in all load conditions shows a positive value oad changes that are simulated on each type of ship shows a difference in the value of GM produced ccording to [35], a positive GM value indicates that the metacentre point $(\mathrm{M})$ is above the gravity point $(G)$ so that this results in good stability conditions.

\subsection{Moving Resistance}

Moving resistance is one of the important parameters needed to see the quality of a ship's feasibility he variety of characteristics and body shape of a ship is one of the factors that can affect the motion resistance of the ship itself arge resistance of a ship can be shown by making a curve that connects resistance to motion and speed he resistance curves on each ship are presented in Figure 17.

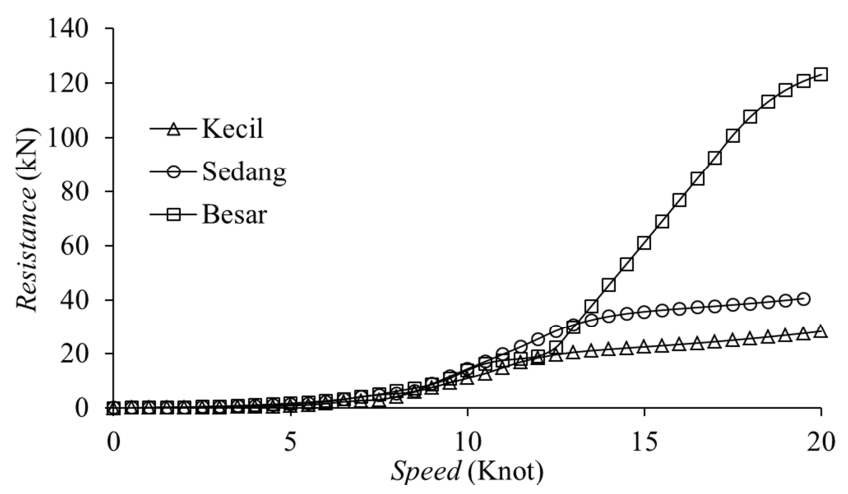

Figure 17. The ship resistance curve for each type of ship.

Based on Figure 17, the results show that large, medium and small ship groups have higher ship resistance value compared to small ship groups he small ship group produces smaller resistance starting from when the ship moves at 1 knot speed, but the resulting resistance value is not too different from the medium and large ship group his makes the large value of motion resistance when a group of small ships reach a smaller service speed compared to other types he speed of service on fishing vessels in the Kendari area is 7 knots he value of motion resistance of small ship groups when they reach service speed is $5.65 \mathrm{kN}$.

The large difference between the large, medium and small groups of resistance began to be seen clearly when the group of ships was reaching speeds of 10 knots he size of the resistance produced by the medium ship group is $15.17 \mathrm{kN}$, while the value of the resistance produced by large and small ship groups is $14.39 \mathrm{kN}$ and $14.25 \mathrm{kN} \mathrm{s}$ speed increases, small vessels have a smaller resistance value compared to large and medium vessels he value of resistance of small ship groups when reaching speed of 20 knots is $24.15 \mathrm{kN}$.

The greater resistance of motion caused by the large value of wetted surface area owned by large and mediumsized vessels ccording to [15], the greater the wetted surface area, the greater the value of the motion resistance of the ship he motion resistance of a ship has a relation to the wetted surface area due to the amount of resistance produced between the ship's body immersed in the water against the friction resistance of the sea water as a fluid medium [36].

\subsection{Rolling Motion Analysis with Rolling Period}

To determine or analyze rolling motion, in this discussion a calculation using the shaking period (TR) method or rolling period of a ship is used the approach formula contained in the Code On Intact Stability book by the International Maritime Organization (IMO) 3.2.2.3 page 14 , namely to large, medium and small ship groups as shown in the table 6 .

Table 6. Rolling Period values of large, medium and small group vessels.

\begin{tabular}{llll}
\hline \multirow{2}{*}{ Clasification } & IMO & Rolling period & \\
\cline { 3 - 4 } & & Value & Result \\
\hline Large & $4,5-7,0$ second & 6,39 second & Fulfilled \\
Medium & $4,5-7,0$ second & 5,23 second & Fulfilled \\
Small & $4,5-7,0$ second & 4,68 second & Fulfilled \\
\hline
\end{tabular}

Initial planning drawing for the flagship 5 GT hand line flagship. 3D images of the flagship ship design are shown in Figure 18.

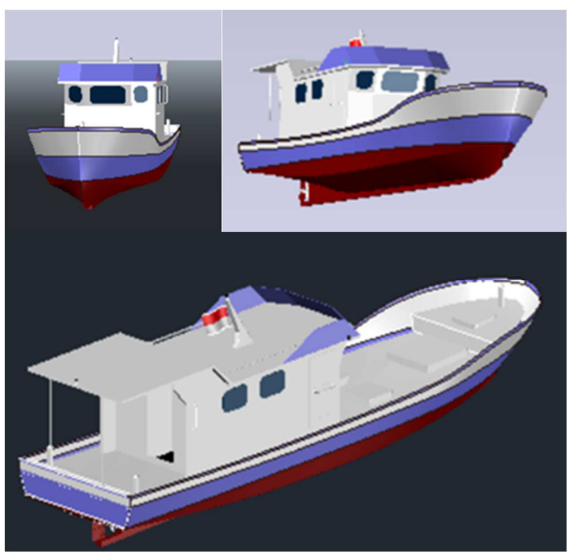

Figure 18. Design 3D fishing vessel. 

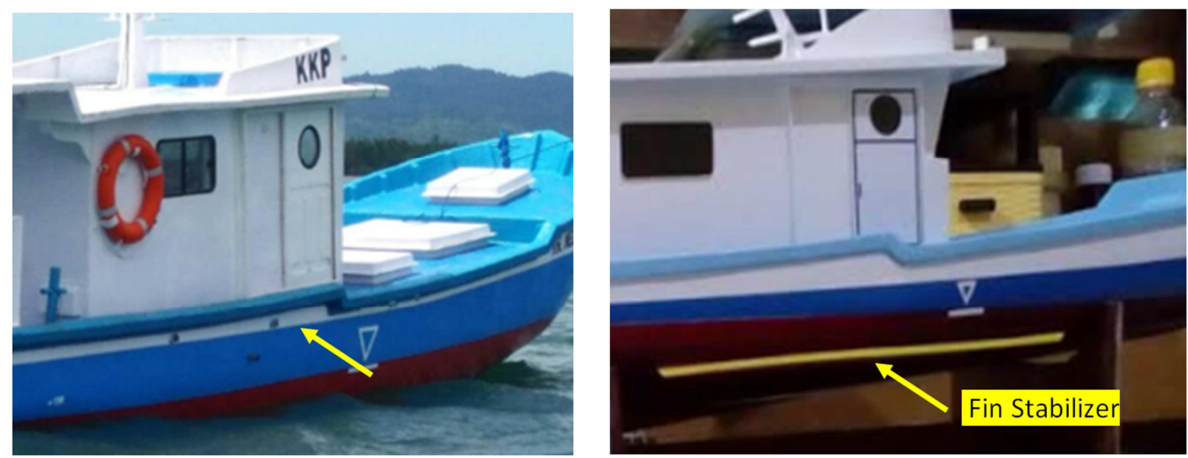

Figure 19. Fin Stabilizer addition to fishing vessel.

The addition of fin stabilizers in the body of the ship to make the ship not too shake especially when the ship is stationary to carry out operations with the hand line.
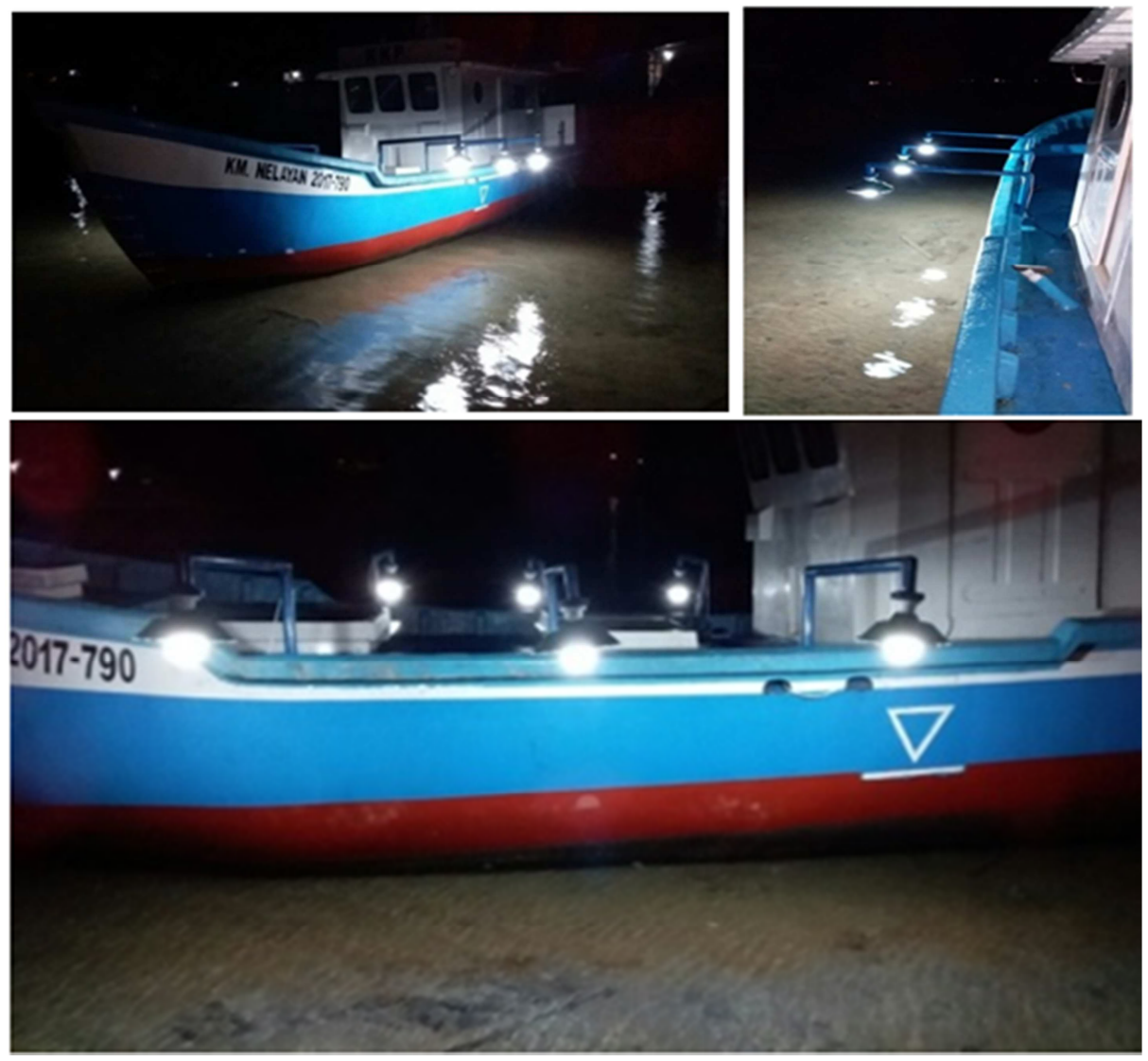

Figure 20. Handline ships with light fishing were tested in Kendari.

Figure 20 shows that the position of the lights used as fishing aids in pairs on the right and left hulls in the center of the ship are 3 pairs of light fishing lights he addition of these lights helps fishermen so that the ship can be operated at night.

\section{Conclusion}

Based on the analysis results, the following conclusions can be drawn:

1. The description of the existing condition of the light fishing boat fleet in Southeast Sulawesi is as follows: a. In the handline ship design group with light fishing there are 3 parts, namely large, medium and small size vessels.

b. Of the three groups, all the designs of the bow height are raked bow ramps which indicate that the shape of the ship there is uniform from the bow height of the bow.

c. The design also has a different longitudinal cross section shape, namely double pointed for small group size vessels and transom for large and medium size vessels.

2. Based on parameter values, ships with medium group 
size, have the best stability value, and also have the greatest resistance value ased on the rolling period value of ships with medium, large and small group sizes, the value is according to the requirements, namely $\mathrm{TR}=4.5-7.0$ seconds.

3. The formulation of superior ship design for the recommended kasko form is the U-bottom form in accordance with the medium group he stability of the flagship ship, the prisoners and the ship's shaking period for full load conditions meet the criteria recommended by IMO.

\section{Recommendations}

It is expected from the results of this research that the Government in this case is the Office of Maritime Affairs and Fisheries Southeast Sulawesi Province developing its fishing fleet in the waters of Southeast Sulawesi with type of handline fleet of size 5 GT made of fiberglass vessels his is based on the potential of fisheries that are still large and in large numbers relatively limited fishing fleet $\mathrm{s}$ for academics Haluoleo University, Kendari can be developed further by fishing using lights or light fishing lines so that productivity and effectiveness Catches from fishermen more results are obtained.

\section{Acknowledgements}

The Team of the Directorate of Fishing Vessels and Fishing Equipment (KKP), BBPI Semarang, BBPT, Ministry of Industry-Directorate General of Industry and Metals and the Indonesian Classification Bureau who always provide moral support and discussions during the research.

Head of the Southeast Sulawesi Province's Fisheries and Maritime Services Office, Haluoleo University, especially Dr a Anadi and all of his staff for their permission and the assistance of facilities during the research.

\section{Appendix}

1. Interview documentation

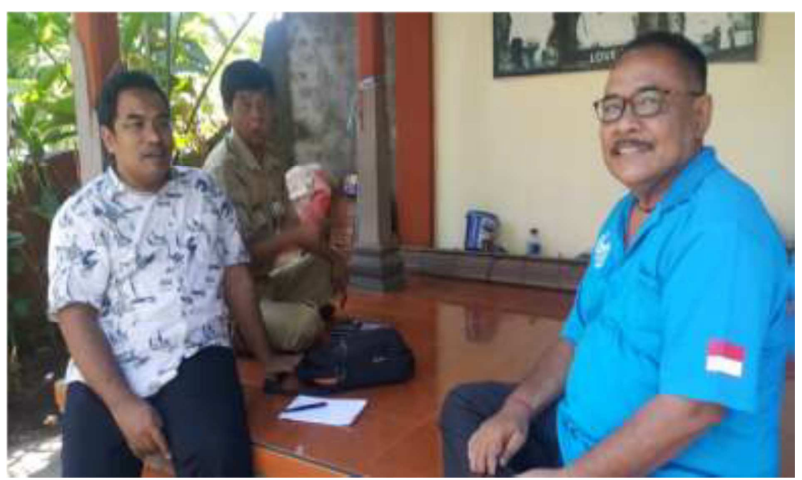

Figure 21. Interview with Mandonga fishermen, Kendari.

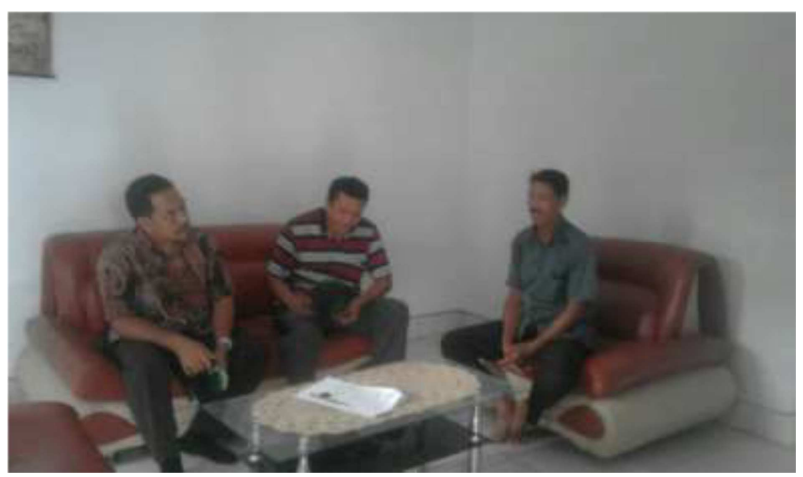

Figure 22. Interview with Abeli fishermen, Kendari.

\section{Results of the FGD with Fishermen in Kendari}

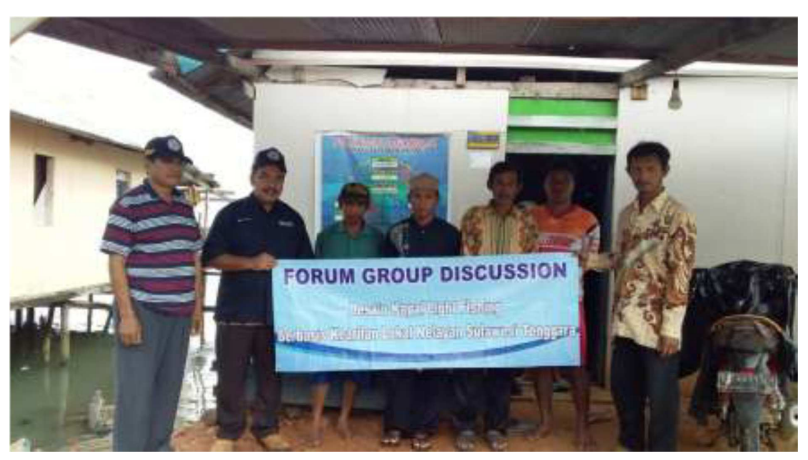

Figure 23. Interview with Poasia fishermen, Kendari.

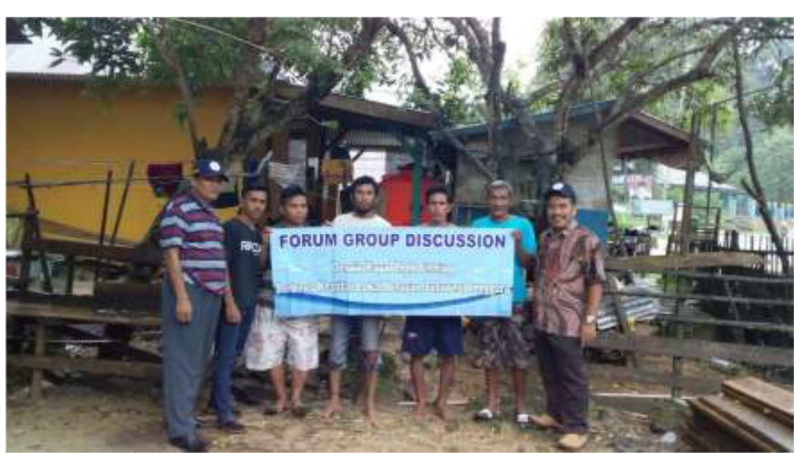

Figure 24. Interview with Kadia fishermen, Kendari.

\section{References}

[1] Tandipuang P. Novita Y, Iskandar BH. 2015. The suitability of INKAMINA 163 operational ship design is based at PPP Sadeng Yogyakarta. National Marine Journal. 10 (2): 103-112.

[2] Rouf ARA, Novita Y. 2006. The study of the shape of fishing boat head in several regions in Indonesia. TORANI. 16 (4): 240-249.

[3] Bangun TNC, Novita Y, Iskandar BH. 2017. Shape of a fishing boat's curved shape (less than 30 GT). Albacore. 1 (2): 127-137.

[4] Fyson J. 1985. Design of Small Fishing Vessels. England: Fishing News Book.

[5] Hardjono S. 2010. Identify the parameter ratios for FRP catamaran passenger ships. Indonesian Journal of Science and Technology. 12 (3): 159-165. 
[6] Zain J. 2010. Study of materials and construction of gill net fishing vessels in Dumai City, Riau Province. Periodical Fisheries Terubuk. 38 (1): 82-94.

[7] Novita Y, Iskandar BH, Imron M, Nurdin HS. 2016. Design of modified purse seine vessels in Bulukumba Regency, South Sulawesi Province. Journal of Fisheries and Maritime Affairs. 6 (2): 125-136.

[8] Eyres DJ. 2001. Ship Contruction: fifth edition. Oxford (UK): Butterworth-Heinemann.

[9] Farhum SA. 2006. South Sulawesi pole and line operational stability and safety study on seas beam waves. Bogor (ID): Institut Pertanian Bogor.

[10] Gillmer TC, B Johnson. 1982. Introduction to Naval Architecture. Maryland (US): Naval Institut Press.

[11] Soegiono T, Sastrodiwangso, Sasongko B, Andrianto P, Soeweify, Moernadi E, Payappo A, Wartono M, Asianto, Sukotjo, Sastrowiyono K. 2006. Shipping Engineering Dictionary. Surabaya (ID): Airlangga University Press.

[12] Kok HGM, Lonkhyusen EGV, Nierich FAC. 1983. Ship Building. Zundort (NL): Martech.

[13] Pangalila FPT. 2010. Static stability of a flattered type of fish boat based at the Aertembaga Ocean Fisheries Port of the City of Bitung, North Sulawesi Province. Journal of Fisheries and Maritime Affairs. 6 (3): 149-155.

[14] Derret DR, Barras B. 2006. Ship Stability for Master and Mates. $6^{\text {th }}$ edition. London (UK): Elsevier Ltd.

[15] Manopo AR, Masengi KWA, Pamikiran RDCh. 2012. Studies of the influence of the shape of the cascade on ring-boat detainees in Tumumpa, Bitung, and Molibagu (North Sulawesi Province). Journal of Fisheries Science and Technology.

[16] Holtrop J. 1984. A statistical re-analysis of resistance and propulsion data. International Shipbuilding Progress. 31 (363): 272-276.

[17] IMO International Martime Organization. 1995. Code on Intact Stability for All Types of Ships. London (GB): IMO.

[18] Bhattacharya R. 1978. Dynamic of Marine Vehicles. New York (US): John Wiley and Son, Inc.

[19] Fachrussyah. ZC, Eduart Wolok, Alfi SR Baruadi, Stella Junus. 2014. Design Characteristics of Katinting Fishing Boat in Gorontalo Province.

[20] Guritno D, Irnawati R, Susanto A. 2016. Characteristics of the main dimensions of purse seine vessels in the Lempasing Coast Fishing Port of Lampung Province. Journal of Fisheries and Maritime Affairs. 6 (1): 21-30.

[21] Palembang S, Luasunaung A, Pangalila FPT. 2013. Study on the design of a 13 GT multifunctional fiberglass fish boat in the shipyard CV Cipta Bahari Nusantara Minahasa, North Sulawesi. Journal of Capture Fisheries Science and
Technology. 1 (3): 87-92.

[22] Tangke U. 2010. Evaluation and development of pole and line design at the Port of Dufa-Dufa, North Maluku Province. Agribusiness and Fisheries Scientific Journal. 1 (2).

[23] Wolok E, Baruadi ASR, Junus S, Fachrussyah ZC. 2016. Katinting Traditional Boat. Gorontalo (ID): Faculty of Fisheries and Marine Sciences, University of Gorontalo.

[24] Azis MA, Iskandar BH, Novita Y. 2017. Ratio of main dimensions and static stability of traditional purse seine vessels in Pinrang Regency. Journal of Tropical Marine Science and technology. 9 (1): 19-28.

[25] Nopandri R, Fauziyah, Rozirwan. 2011. The stability of the bottom gilnet vessels at the Sungailiat Archipelago Fishery Port, Bangka Belitung. Maspari Journal.

[26] BPPT Badan Pengkajian dan Penerapan Teknologi. 2002. Dissemination of Conventional Technology for Fishing Boat Design in Cilacap. Suharbiyanto RB, editor. Jakarta (ID): BPPT.

[27] Ayodhyoa. 1972. Fishing Boat. Bogor (ID). Bogor Agricultural Institute.

[28] Novita Y, Iskandar BH. 2008. The relationship between the shape of a ship's model boat and its motion detector. Newsletters PSP. 17 (3): 315-324.

[29] Santara A, Purwangka F, Iskandar BH. 2014. Work safety equipment on slerek boats in PPN Pengambengan, Jembrana Regency, Bali. PSP Science and Technology Journal. 1 (1): 53-68.

[30] Yaakob O, Lee TE, Wai LY, King KK. 2005 Design of Malaysian fishing vessel for minimum resistance. Jurnal teknologi. 42 (A): 1-12.

[31] Susanto A, Iskandar BH, Imron M. 2011. Evaluation of the design and stability of fishing vessels in Palabuhanratu (case study of PSP 01). Marine Fisheries. 2 (2): 213-221.

[32] Susanto A. 2010. Evaluation of the design and stability of fishing vessels in Palabuhanratu (case study ship PSP 01) [thesis]. Bogor (ID): Bogor Agricultural University.

[33] Paroka D. 2018. Geometry characteristics and their influence on the stability of Indonesian ro-ro ferries. Ship. 15 (1): 1-8.

[34] Novita Y, Martiyani N, Ariyani RE. 2014. The quality of the stability of the Palangkratu Payang ship is based on the distribution of the cargo. PSP Science and Technology Journal.

[35] Daud SA, Sianturi, Permana SM. 2013. Analysis of the stability of the operational design of a 20 GT fishing boat in Palabuhanratu. National Marine Journal.

[36] Dariansyah MR. 2018. The suitability of the fishing boat head forms is based on the group of fishing gear operation methods. Bogor Agricultural Institute. 


\section{Biography}

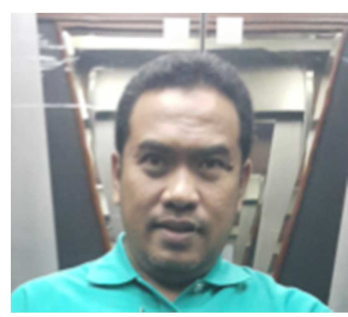

Agus Wahyu Santoso was born in Mojokerto on the 10th of August 1973, from Koesen Hernadijaya and Mrs. Siti Kalimah. In 1992 continued in the State Polytechnic program Shipping, Sepuluh November Institute of Technology (ITS) Surabaya, graduated 1995, then continued with a bachelor at ITS Surabaya in 1996, graduated 1999. 2000 had the opportunity to studies Postgraduate Masters of Engineering at ITS Surabaya, graduated November 2002. The author work the Ministry of Maritime Affairs and Fisheries in December 2002 until now. In 2016 studies at Doctoral Program at the Institute of Agriculture Bogor (IPB) with the Sea Fisheries Technology. 